\author{
مسببات الفجوة الإرشادية للمربيات في مجال

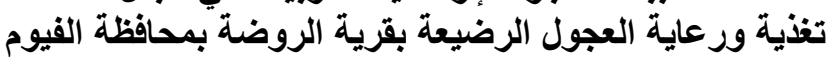

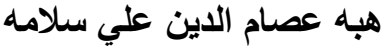 \\ معهز بحوث الارشاد الزر اعى والتنمية الريفية
}

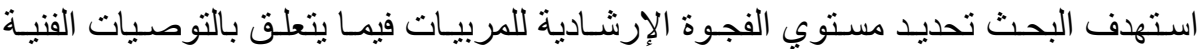

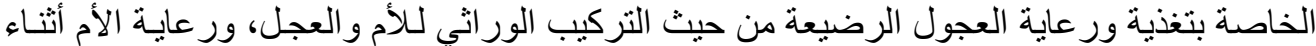

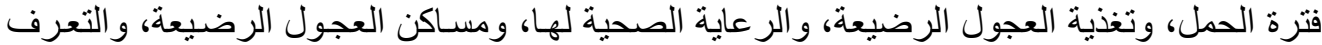

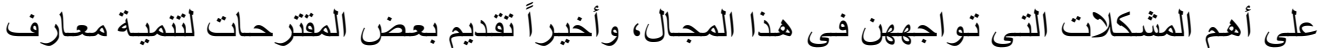

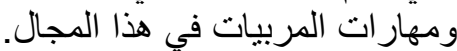

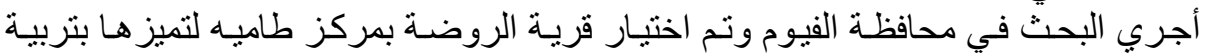

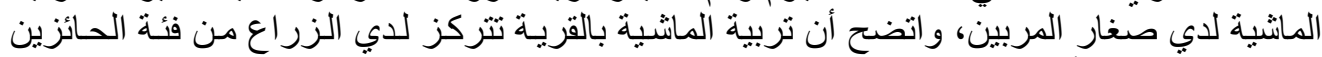

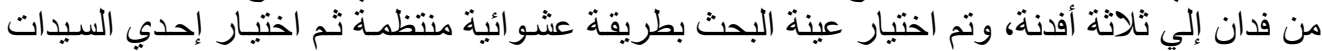

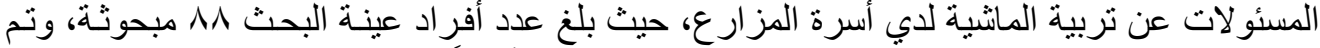

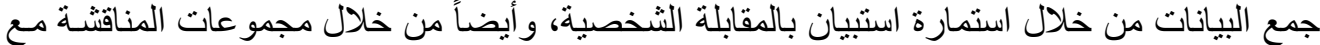

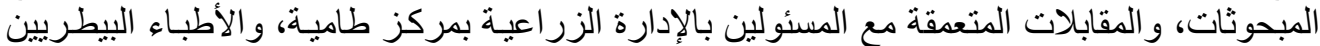

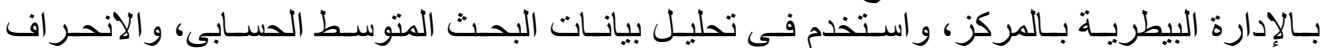

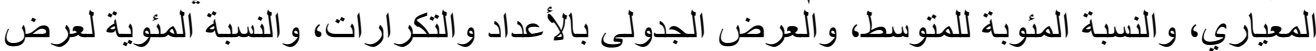

بيانات المقابلات الثخصية.

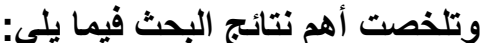

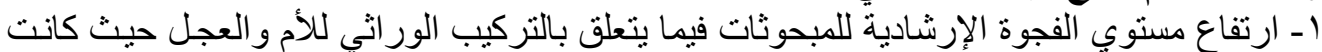

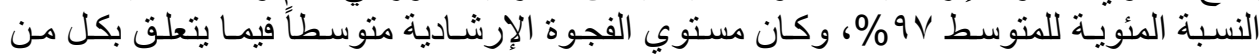

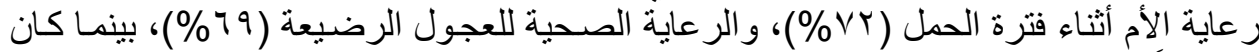

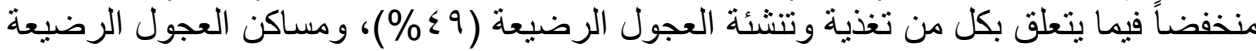

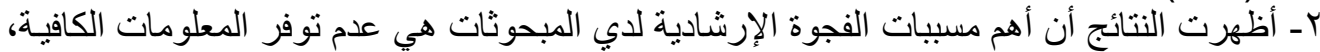

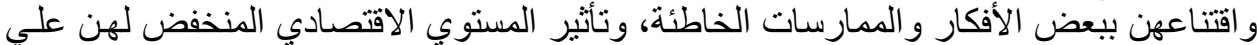

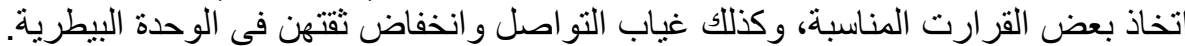

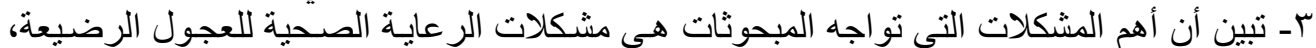

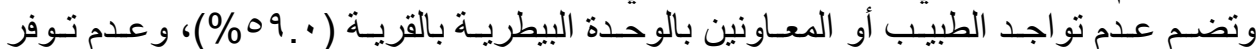

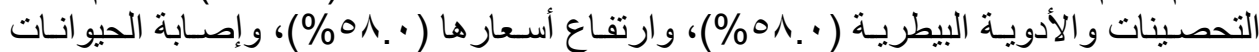

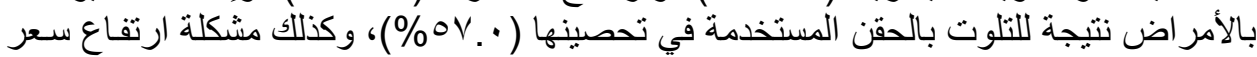

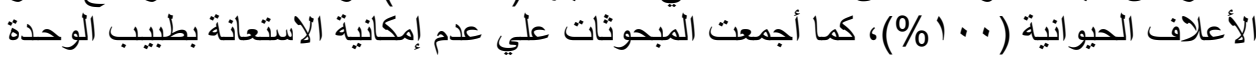
البيطرية في حالات عسر الولادة.

المقدمة والمشكلة البحثية

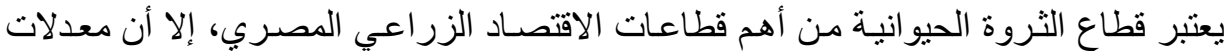

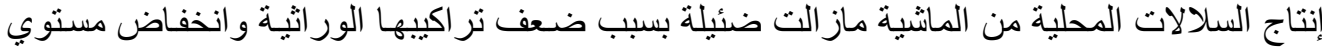

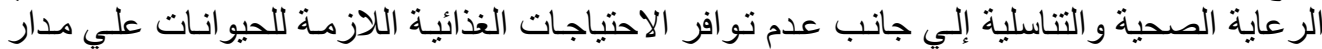

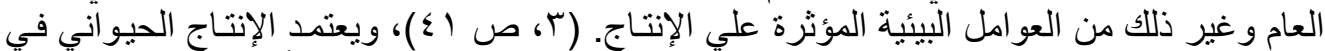

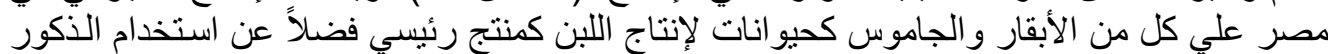

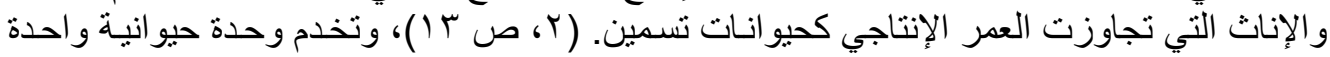

Fayoum J. Agric. Res. \& Dev., Vol. 27, No.1, January, 2013 
$\checkmark$.

كل 7 أفر اد تقريباً رغم ضعف إنتاجها، بينما بصل نصيب الفرد في الأرجنتين علي سبيل المثال إلي

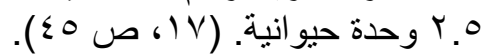

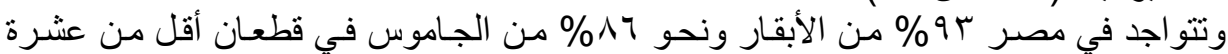

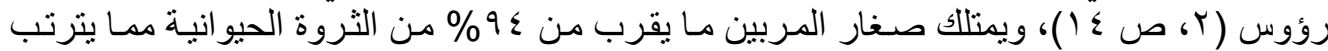

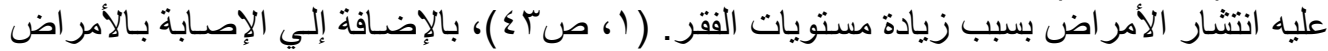

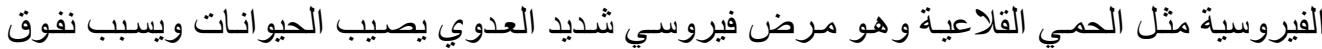

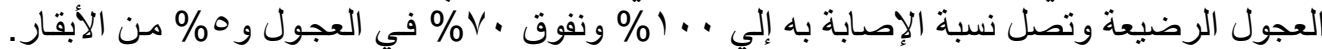

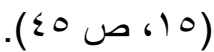

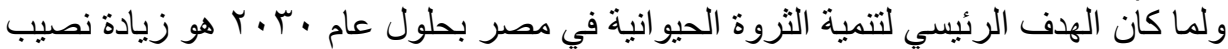

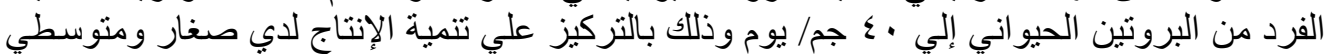

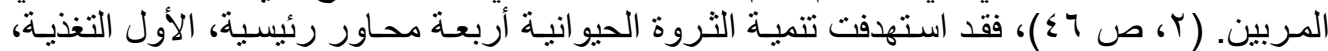

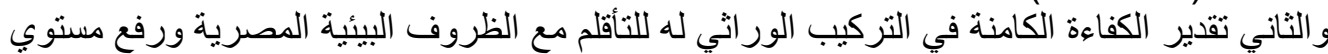

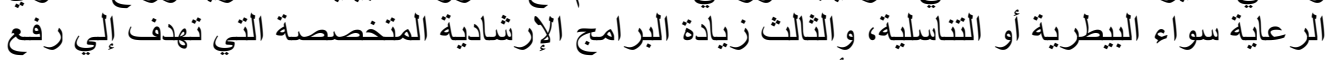

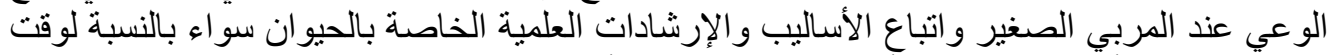

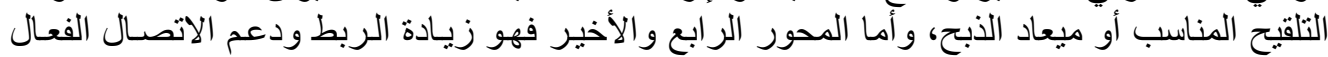

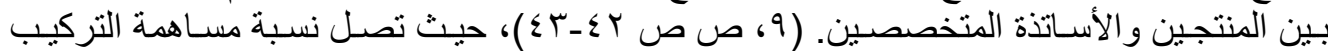

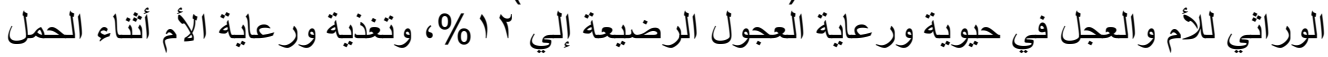

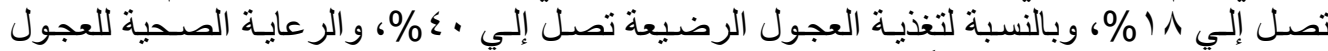

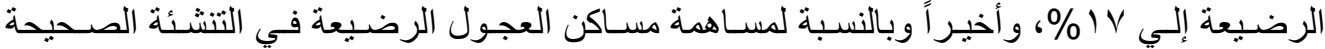

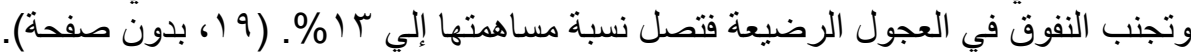

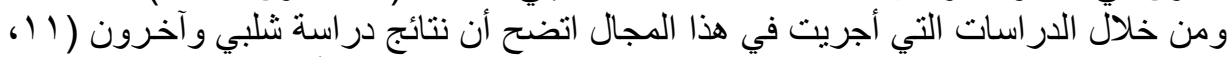

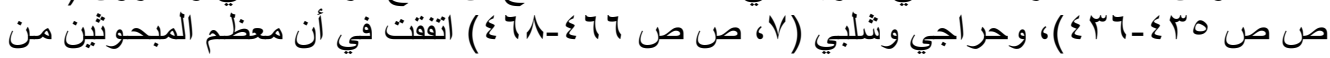

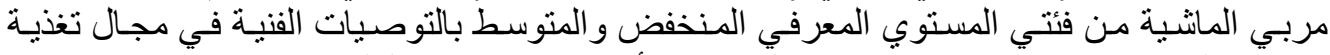

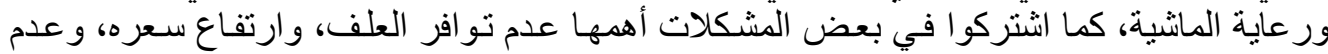
وجود وحدات بيطرية، وارتفاع تكاليف التغذية.

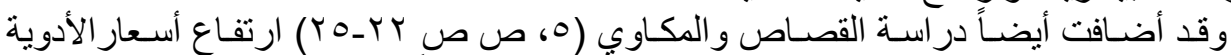

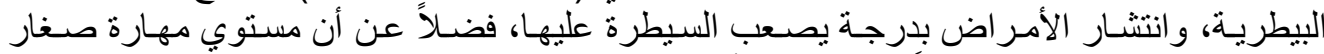

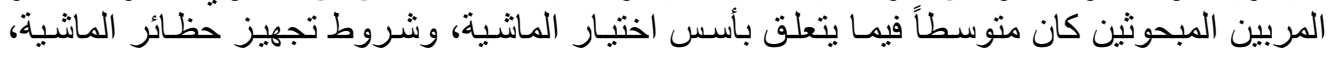

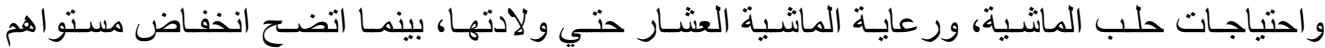

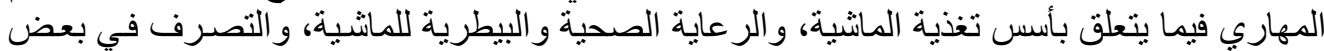

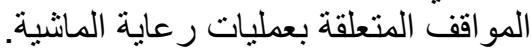

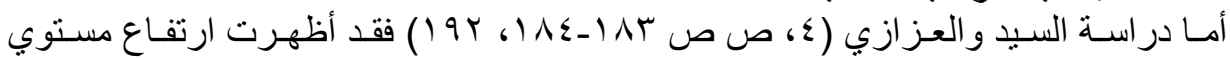

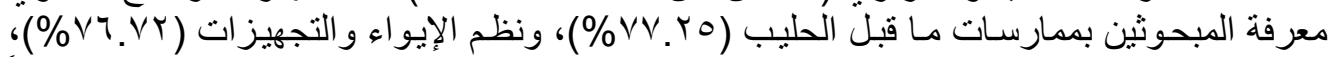

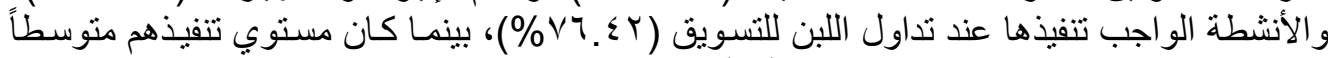

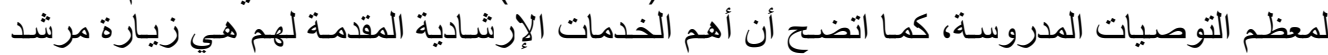

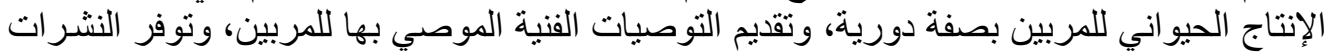

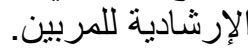

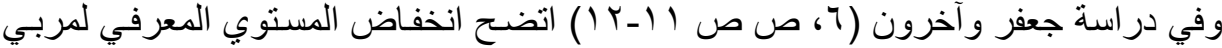

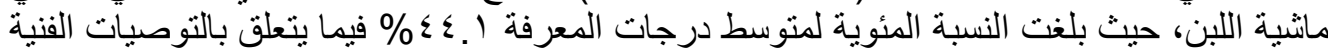

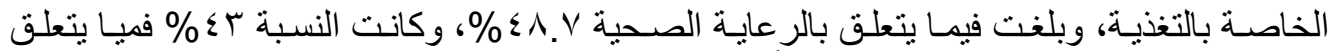

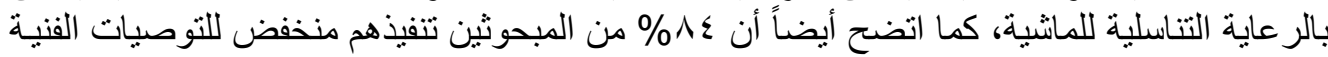
المدروسة.

Fayoum J. Agric. Res. \& Dev., Vol. 27, No.1, January, 2013 
وتوضح الدر اسات السابقة بصفة عامة انخفاض المستوي المعرفي لمربي المانشية في المناطق

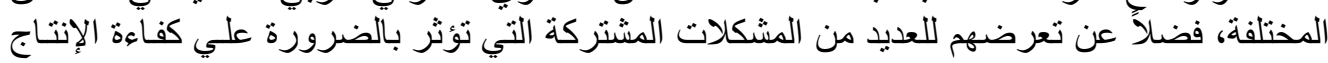

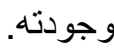

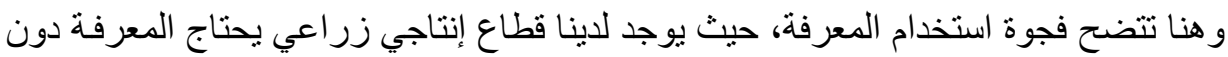

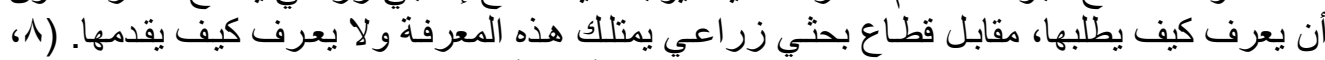

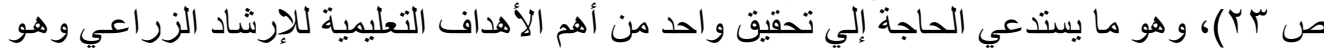

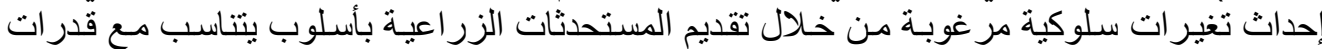

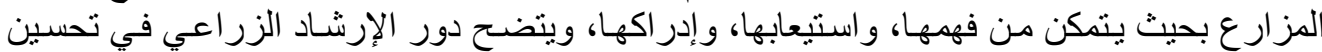

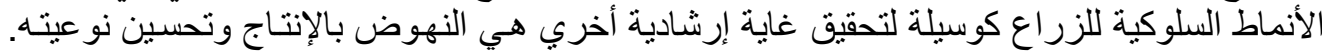

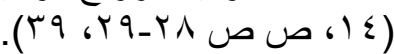

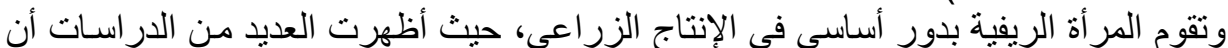

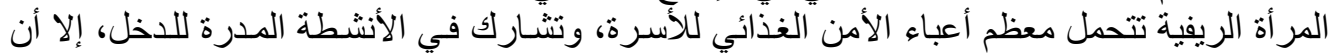

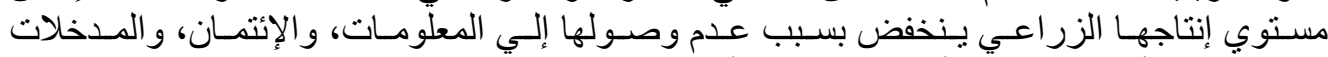

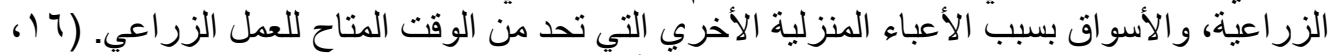

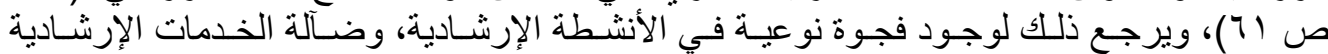

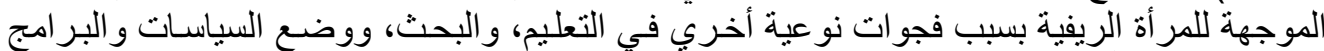

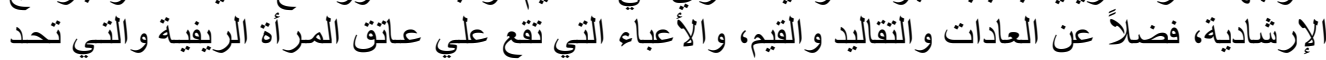

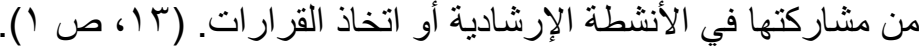

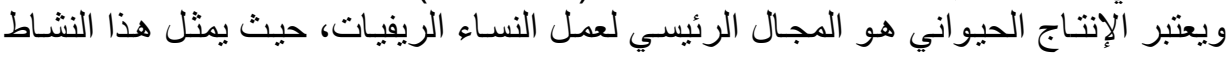

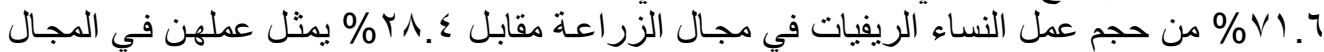

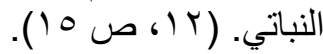

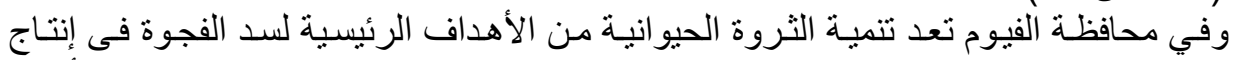

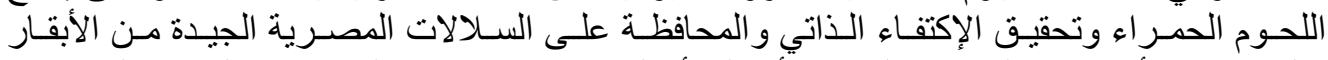

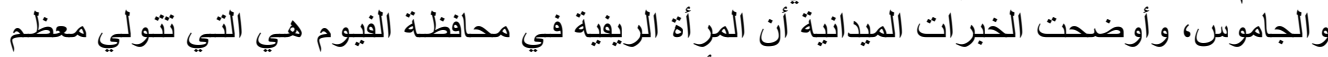

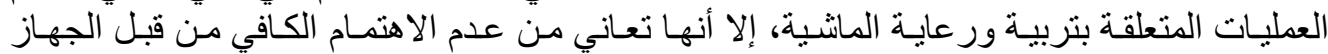

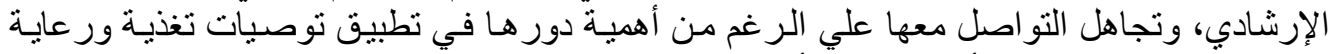

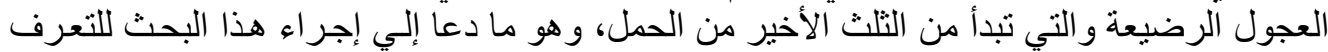

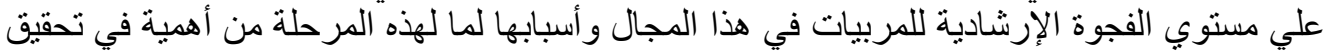

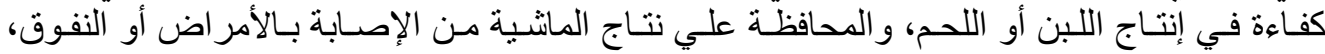

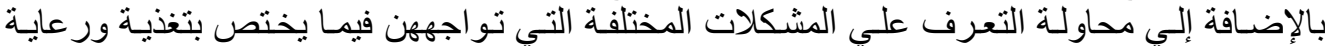

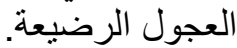

أهمية البحث البث

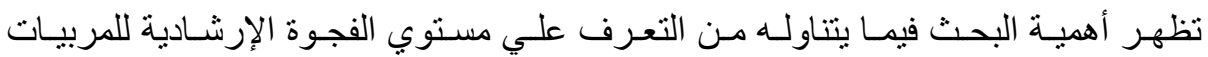

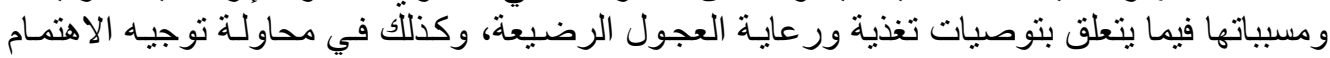

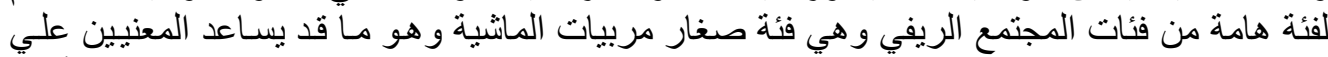

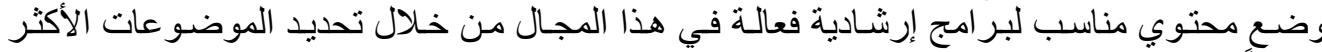
إلحاحاً، و الفئات الو اجب استهدافها، ومساعدة المربيات علي تجاوز المشكلات التي تو اجهرن. 
VY

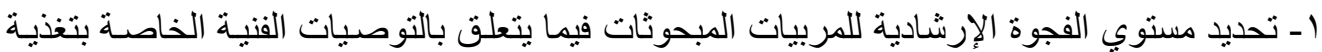

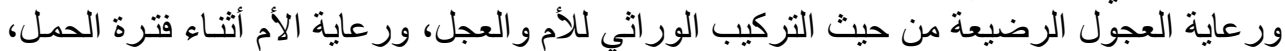

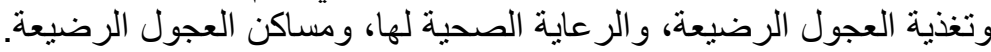

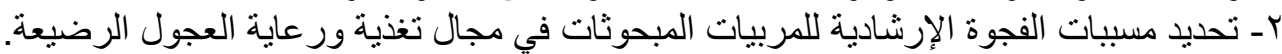

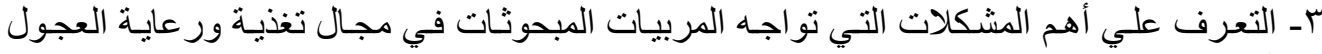

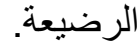

عـ تقديم بعض الرضعة المقترحسات لتتميـة معسارف ومهـار ات المربيـات في مجـال تغذيـة ور عايـة العجـول

الرضيعة.

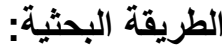

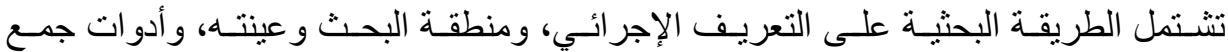
البيانات، وقياس المتغير ات البحثية، وأدوات التئية التحليل الإحصنئي.

أولاً: التعريف الإجرائي البني

الفجوة الإرشادية الإجراية

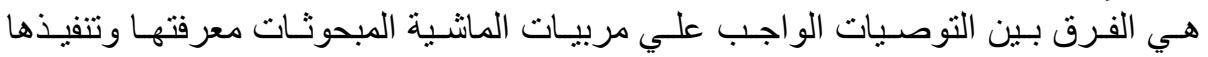

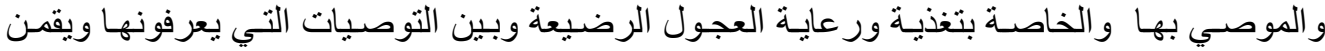

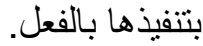

تانياً: منطقة البحث وعينته

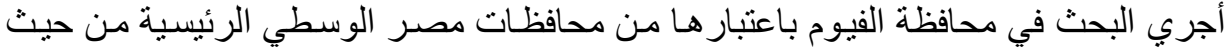

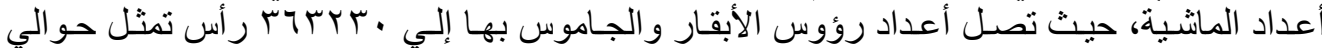

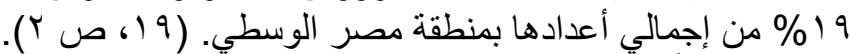

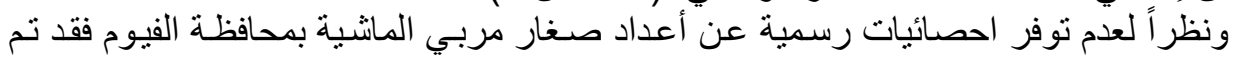

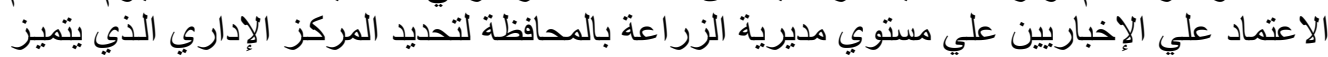

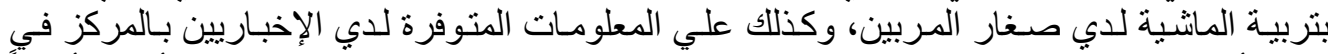

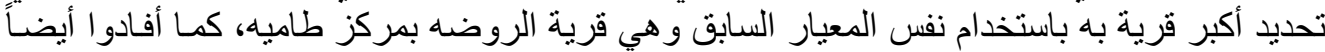

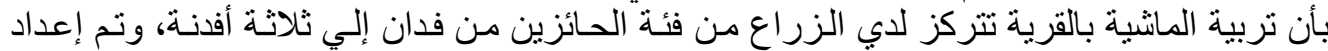

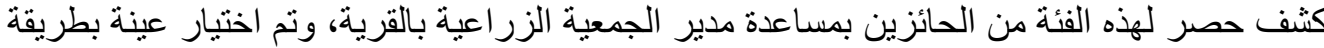

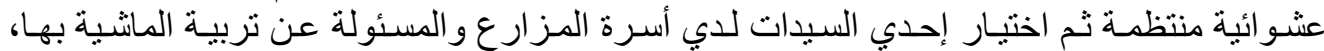

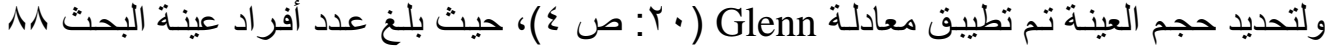

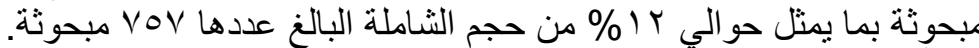

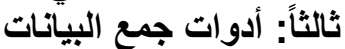

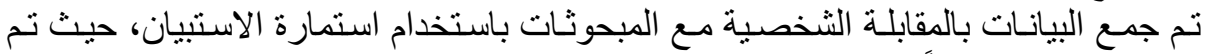

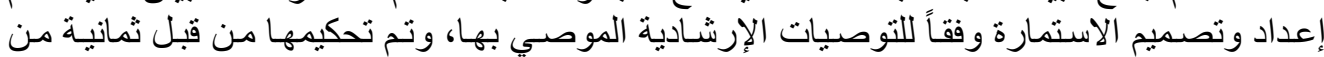

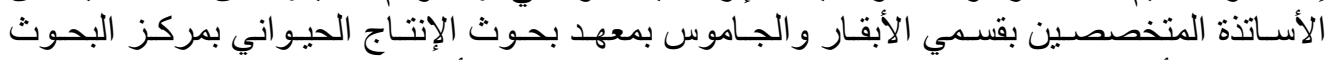

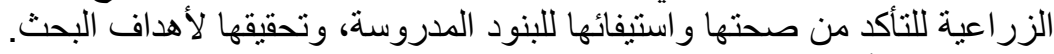

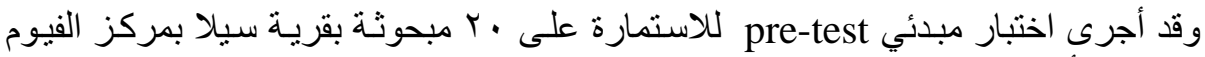

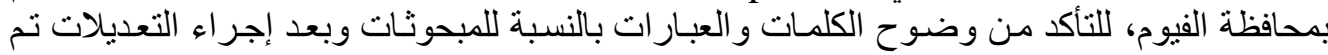

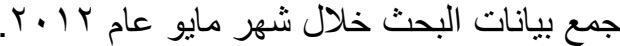

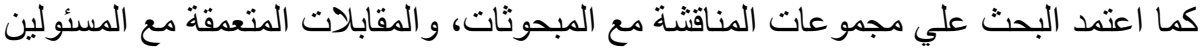
بالإدارة الزراعية بمركز طاميه، وكذللك الأطباء البيطريين بالإدارة البيطرية بالمركز .

رابعاً: قياس المتغيرات البحثية ا- مستوي الفجوة الإرشادية" للمربيات المبحوثات في مجال تغذية ورعاية العجول الرضيعة

Fayoum J. Agric. Res. \& Dev., Vol. 27, No.1, January, 2013 
Vr

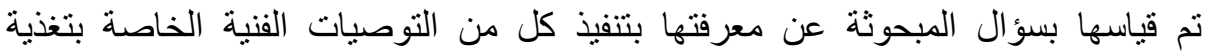

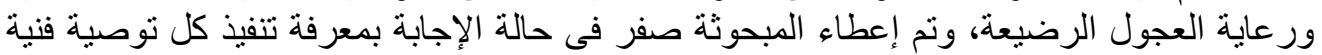

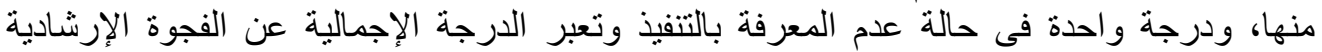

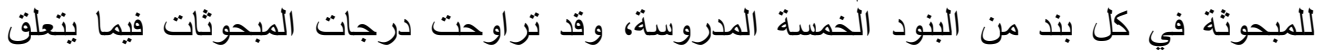

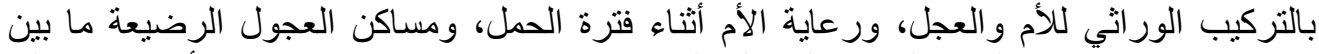

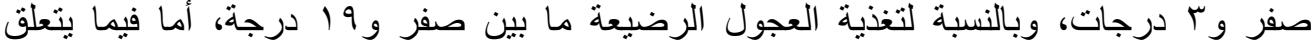

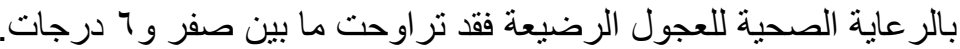

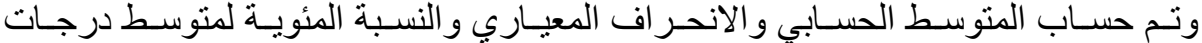

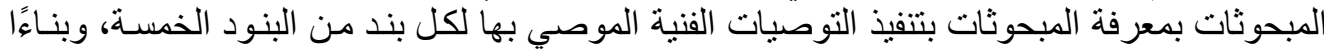

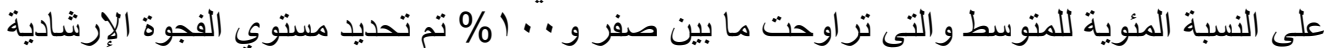

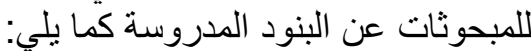
ـ مستوي الفجوة الإرشـادية منذفض: إذا كانت النسبة المئويـة لمتوسط درجات المبحوثنات أقل من $\% 0 .$. - مستوي الفجوة الإرشادية منوسط: إذا كانت النسبة المئوية لمتوسط درجات المبحوثات . . •\% من إلى

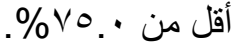

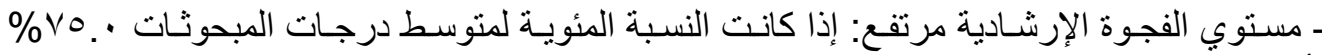
فأكثر. خامساً: أدوات التحليل الإحصائي

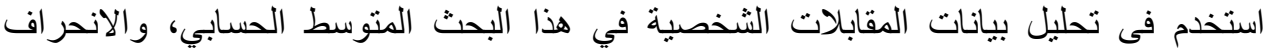

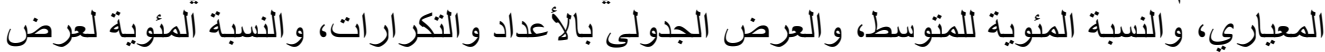

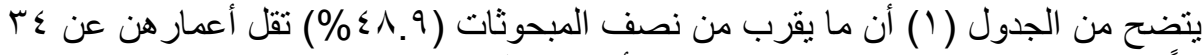

$$
\text { وصف عينة البحث }
$$

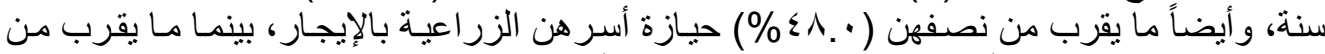

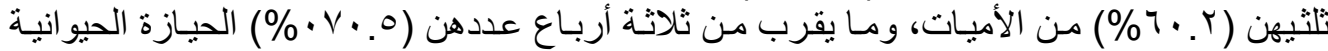
لأسر هن هي بغرض الن التربية.

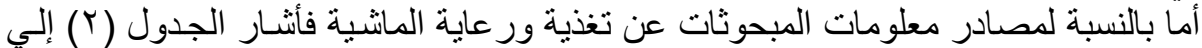

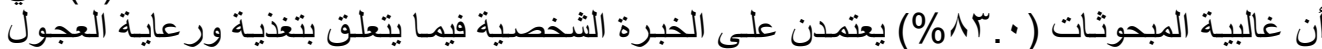

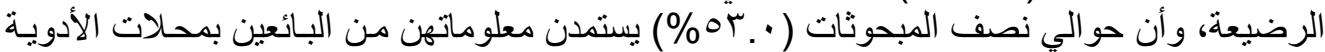

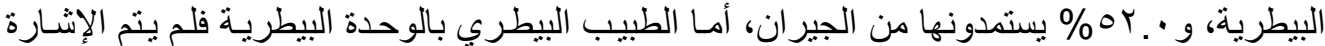

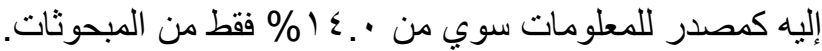

جدول (1): توزيع المبحوثات وفقاً لبعض الخصائص والصفات المميزة لهن

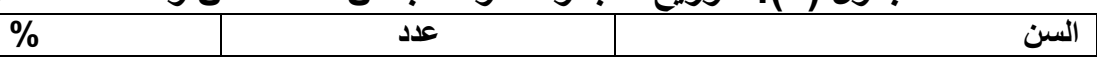

Fayoum J. Agric. Res. \& Dev., Vol. 27, No.1, January, 2013 
V $\varepsilon$

\begin{tabular}{|c|c|c|}
\hline$\varepsilon \wedge .9$ & $\varepsilon r$ & منخفض (أقل من ـ س سنة) \\
\hline rr. & rq & متوسط (؟r- أقل من •0 سنة) \\
\hline $1 \wedge . Y$ & 17 & مرتفع (·0 سنة فأكثر) \\
\hline $1 \cdots$ & $\Lambda \wedge$ & الإجمالي \\
\hline \multicolumn{3}{|r|}{ نوع الحيازة الزراعية } \\
\hline ro.. & 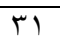 & ملك \\
\hline$\varepsilon \wedge$. & $\varepsilon r$ & إيجار \\
\hline IV.. & 10 & ملك + إيجار \\
\hline $1 \cdots$ & $\Lambda \wedge$ & الإجمالي \\
\hline \multicolumn{3}{|r|}{ الحالة التعليمية } \\
\hline $7 \cdot . Y$ & or & أميه \\
\hline TO.. & TY & تقر أ وتكتب \\
\hline $1 \leqslant . \wedge$ & $1 \pi$ & حاصلة علي مؤهل \\
\hline $1 \cdots$ & $\Lambda \wedge$ & الإجمالي \\
\hline \multicolumn{3}{|r|}{ الغرض من تربية العجول } \\
\hline$V \cdot .0$ & $\pi t$ & التربية \\
\hline 14.0 & 11 & التسمبن \\
\hline IV.. & 10 & بيع بتلو \\
\hline $1 \ldots$ & $\Lambda \Lambda$ & الإجمالى \\
\hline
\end{tabular}

جدول (ץ): توزيع المبحوثات وفقاً لتكرار الإشارة لمصادر معلوماتهن عن تغذية ورعاية الماشية

\begin{tabular}{|c|c|c|}
\hline$\%$ & تكرار & مصادر المعلومات \\
\hline Ar. & $V T$ & 1- الخبرة الشخصية \\
\hline or. & $\varepsilon \vee$ & r- محلات الأدوية البيطرية \\
\hline or. & $\leqslant 7$ & " الجيران \\
\hline $1 \varepsilon$. & Ir & ع - الطبيب البيطري بالوحدة البيطرية \\
\hline r. & $r$ & 0ـ محلات الأعلاف \\
\hline r.t & r & 7- وسائل الإعلام (قناة مصر الزراعية) \\
\hline
\end{tabular}

ألتائج البحثية: مستوي الفجوة الإرشـادية للمربيات المبحوثات فيمـا يتعلق بالتوصيات الفنية الخاصة بتغذيـة

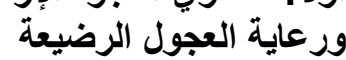

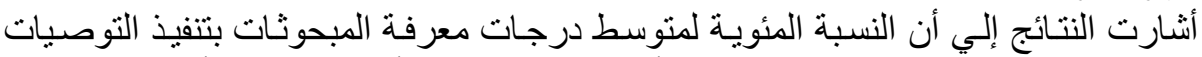

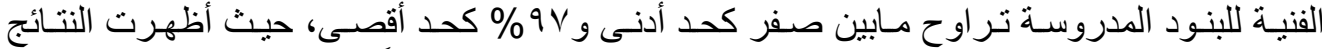

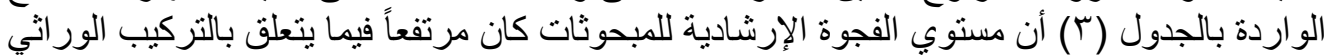
للأم و العجل، وبلغت النسبة المئويـة لمتوسط درجـات معرفة المبحوثنات بتنفيذ التوصيات الفنيـة لهذا

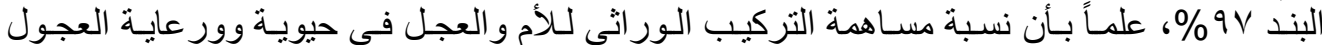

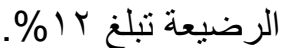

كما اتضح أن مستوي الفجوة الإرشادية للمبحوثات كان متوسطاً فيما يتعلق بر عاية الأم أثتاء

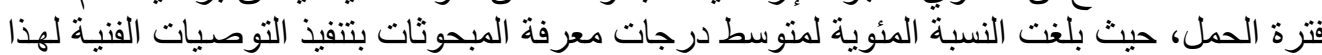

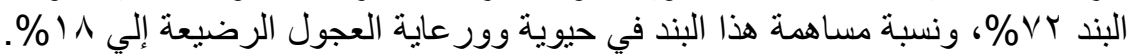

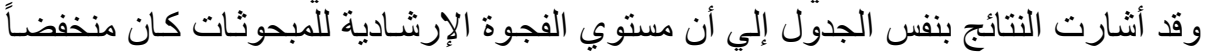

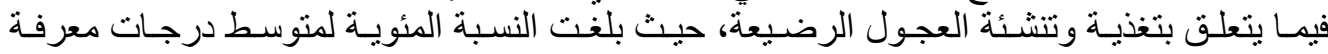

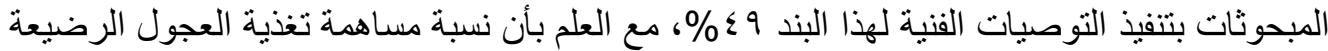

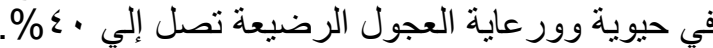

Fayoum J. Agric. Res. \& Dev., Vol. 27, No.1, January, 2013 


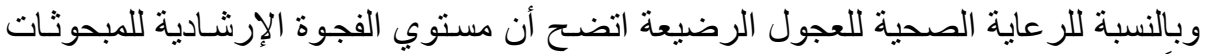

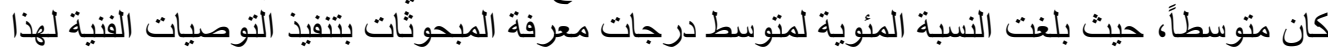

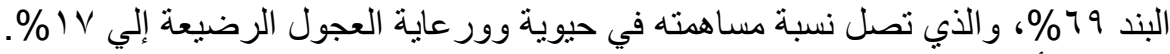

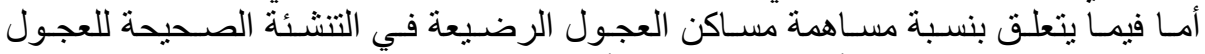

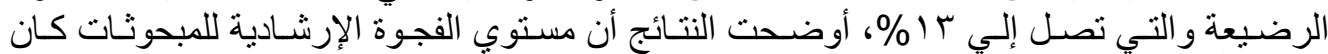

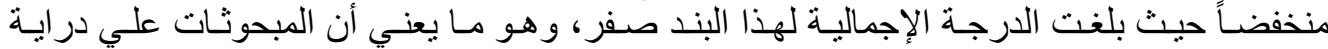
صحيحة بشروط الحظيرة المناسبة.

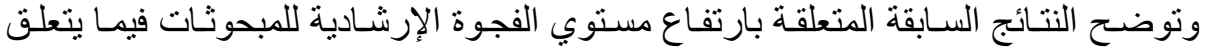

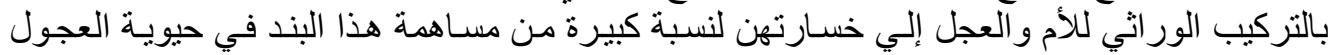

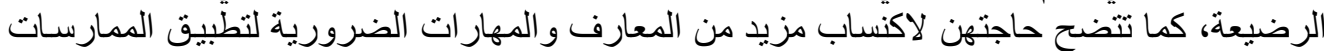

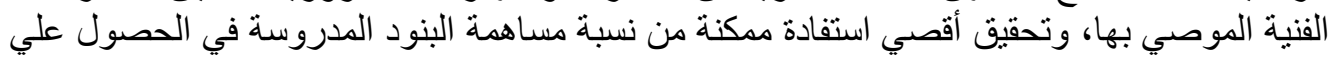

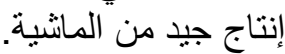

جذول (ץ)): المتوسط الحسابي والإنحراف المعياري والنسبة المئوية للمتوسط لمستوي الفجوة الإرشادية

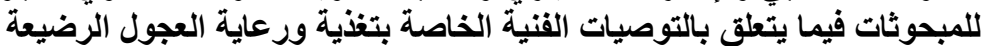

\begin{tabular}{|c|c|c|c|c|}
\hline مستوى الإرشادية & $\begin{array}{c}\% \\
\text { للمتوسط }\end{array}$ & الالعيراف & الحستوسطي & البند \\
\hline مرتفع & $9 V$ &.,$Y V Y$ & Y.9Y & 1- التركيب الوراثي للأم والعجل \\
\hline متوسط & VY & $\cdot . T A r$ & T.IV & r- رعاية الأم أثناء فترة الحمل \\
\hline منخفض & $\leqslant 9$ & $\cdot .117$ & Q.r & r- تغذية وتنشئة العجول الرضيعة \\
\hline متوسط & 79 & Y.Y.T & $\varepsilon .9$ & ــ الرعاية الصحية للعجول الرضيعة \\
\hline منخفض & صفر & صفر & صفر & هـ مساكن العجول الرضيعة \\
\hline
\end{tabular}

ثانياً: مسببات الفجوة الإرشادية للمربيات المبحوثات في مجال تغذية ورعاية العجول الرضئ الرضيعة

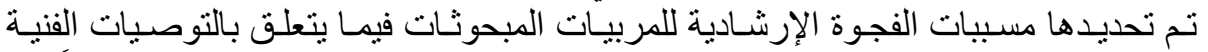

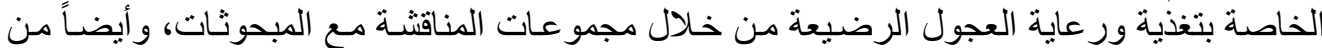

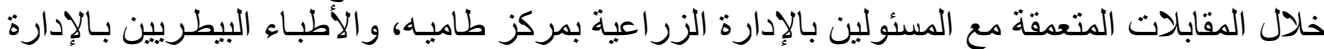

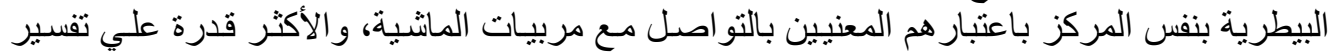

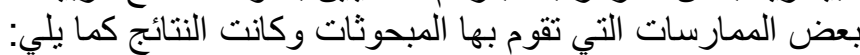

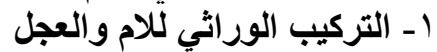

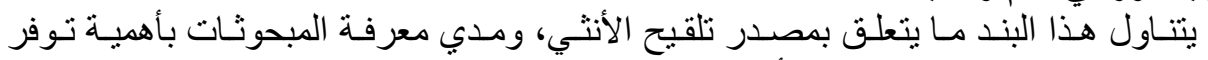

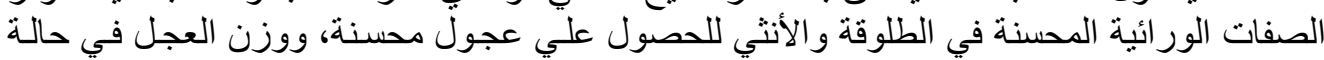

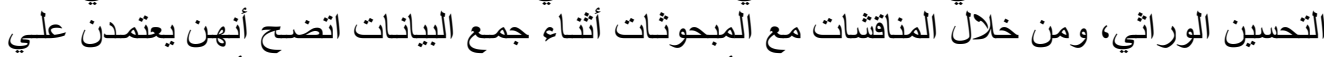

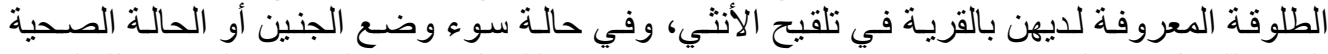

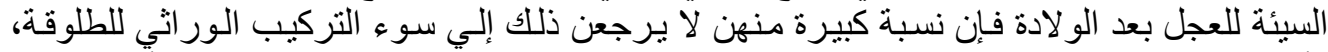

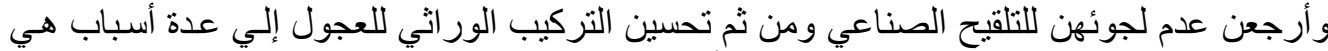

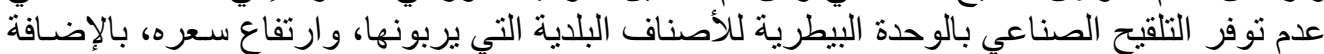

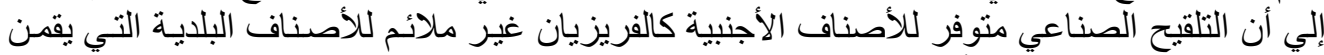

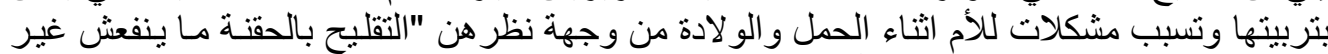

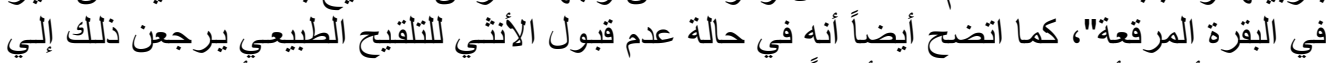

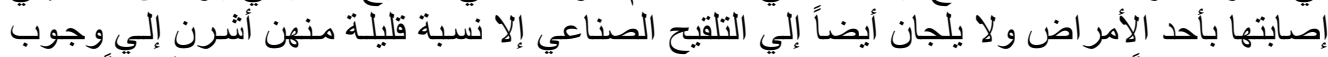

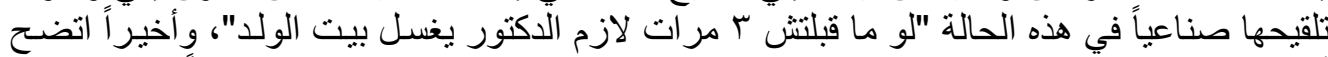

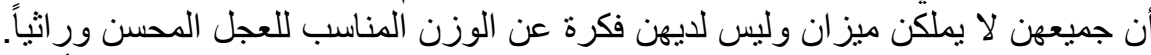

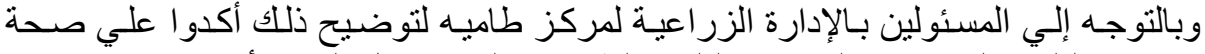

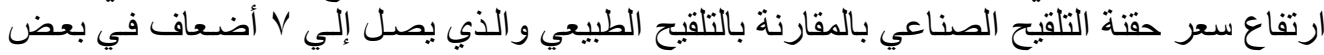

Fayoum J. Agric. Res. \& Dev., Vol. 27, No.1, January, 2013 


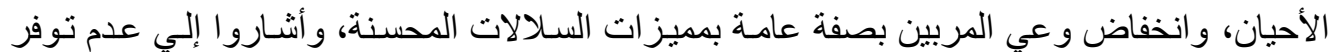

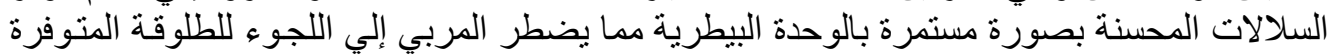

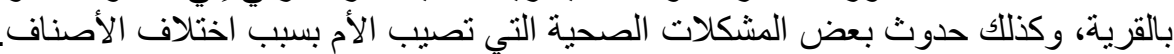

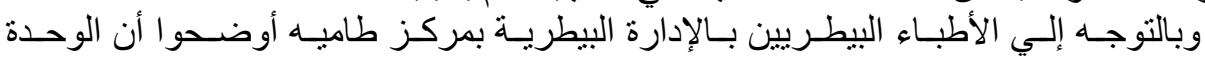

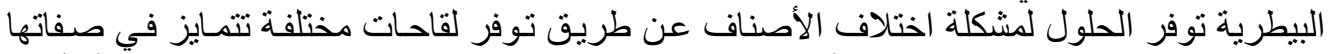

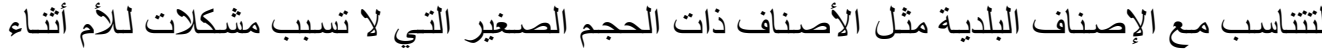

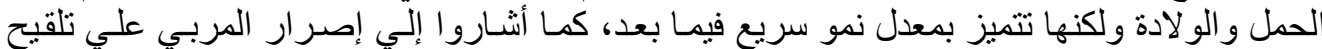

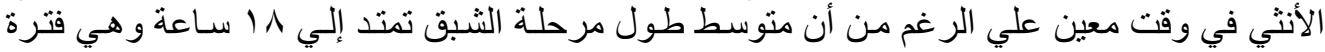

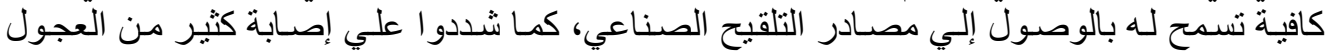

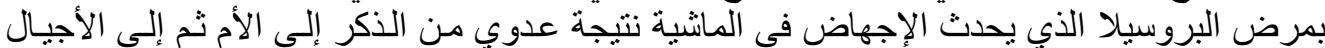

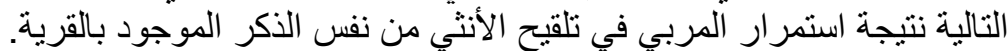

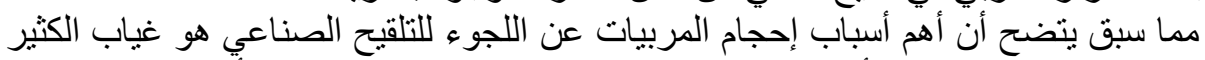

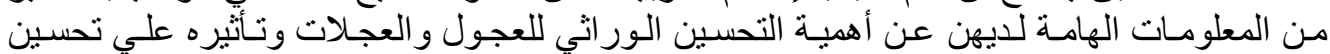

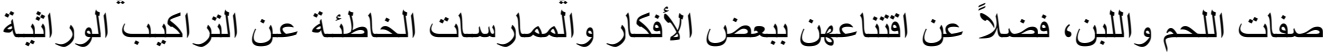

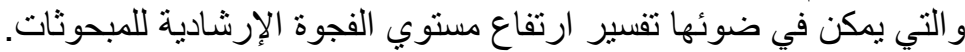

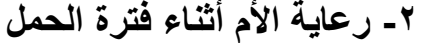

ويتعلق هذا البند بكمية ونو عية العليقة المقدمة للأم وبصفة خاصة خلائل خلال الثلاثة أشهر الأخيرة

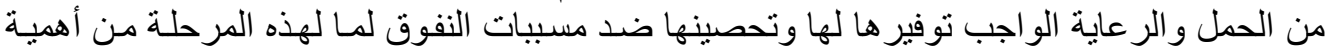

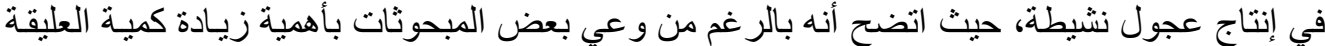

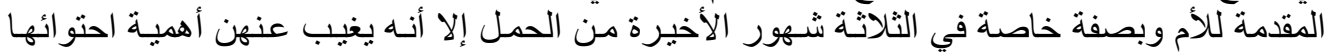

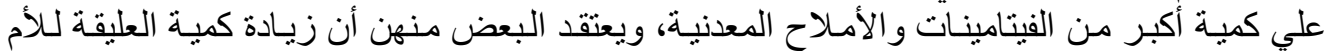

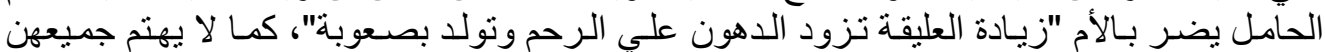

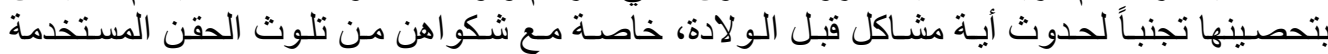

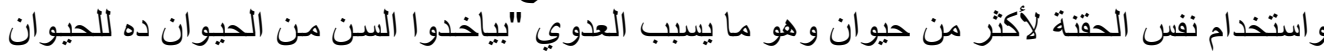

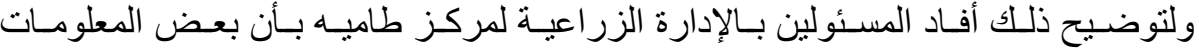

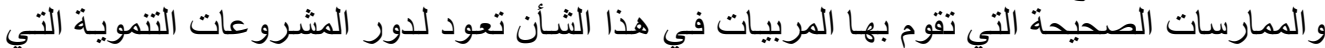

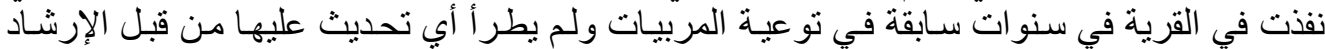

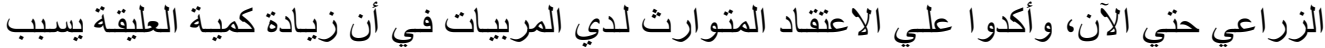

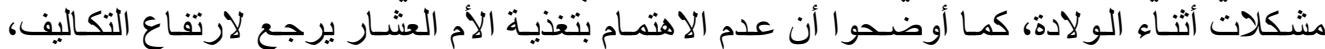

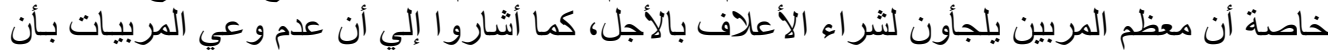

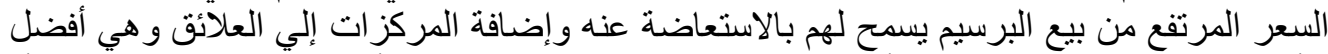

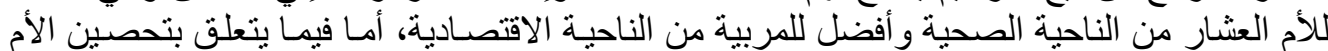

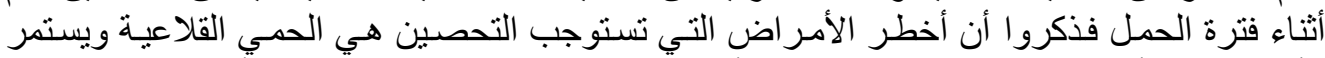

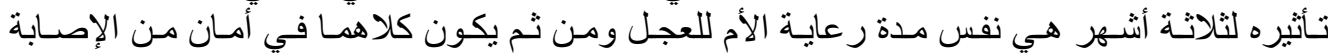

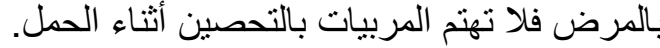

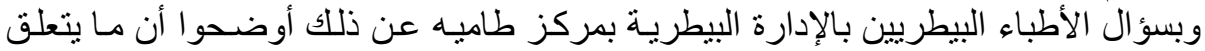

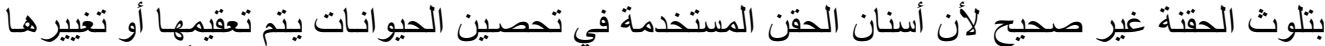

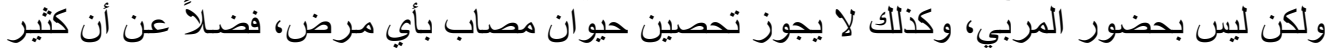

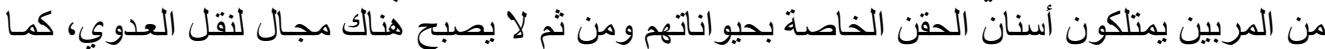

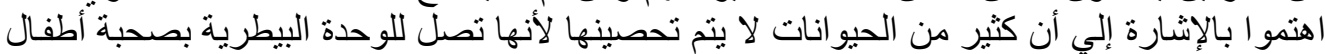

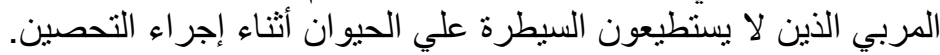

Fayoum J. Agric. Res. \& Dev., Vol. 27, No.1, January, 2013 


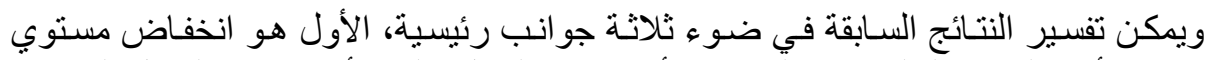

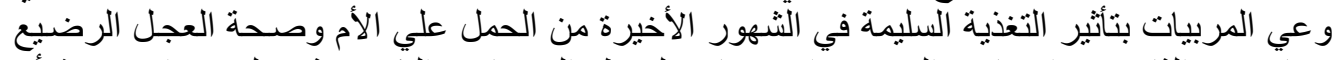

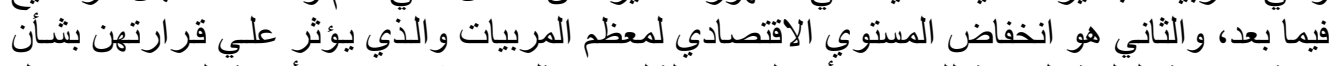

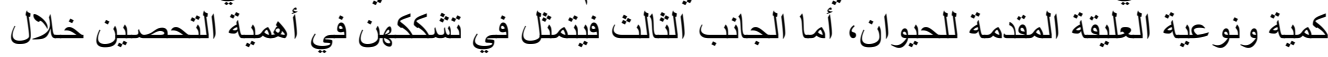
فترة الجفاف في وقاية العجول الرضيعة المنية من مسببات النفوق.

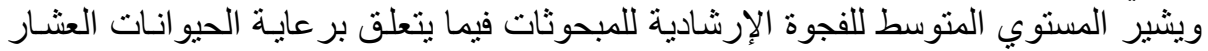

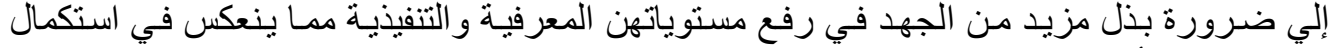

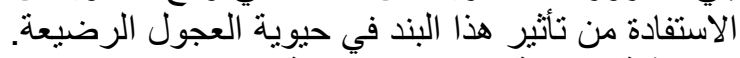

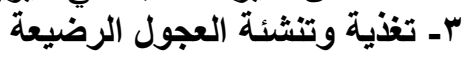

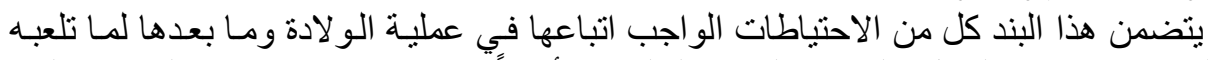

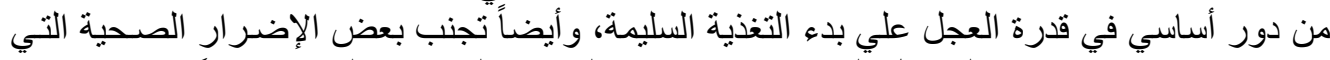

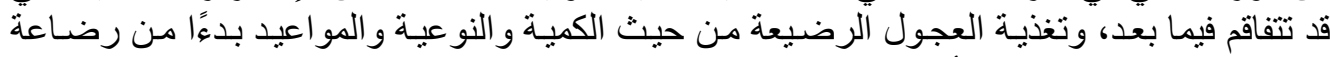

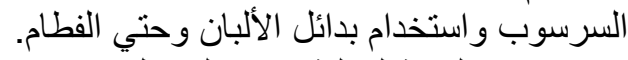

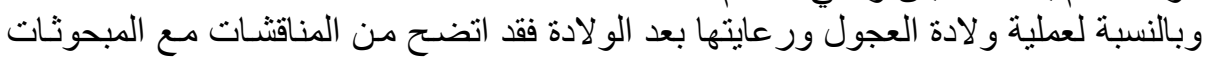

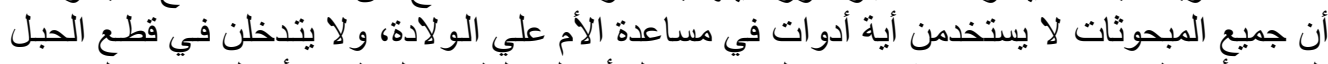

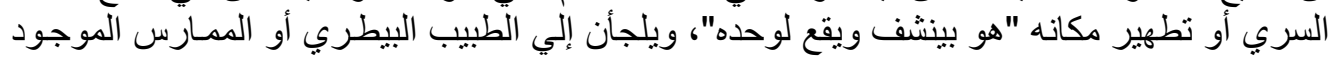

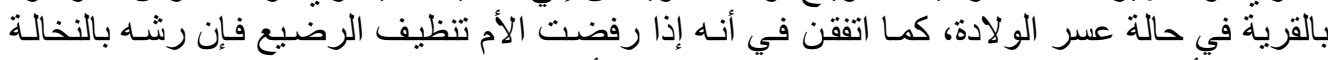

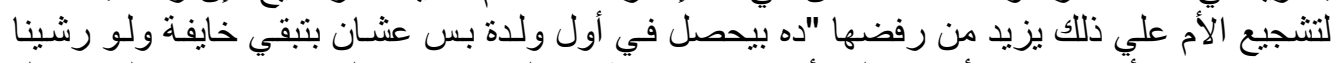

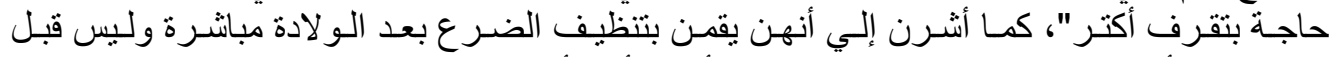

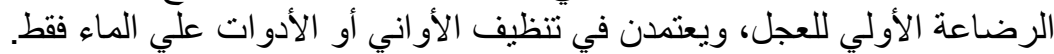

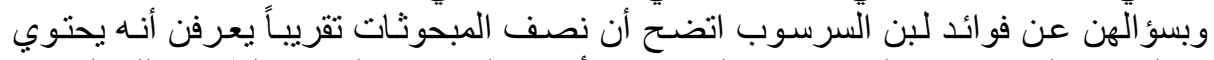

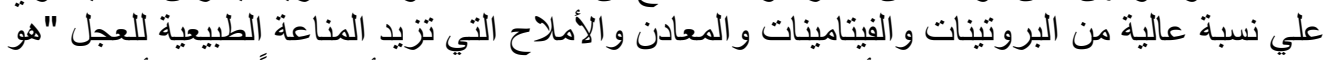

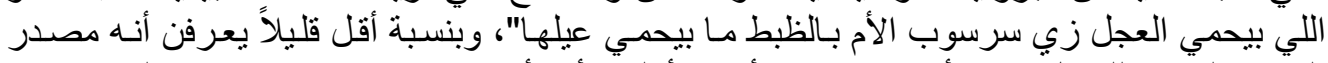

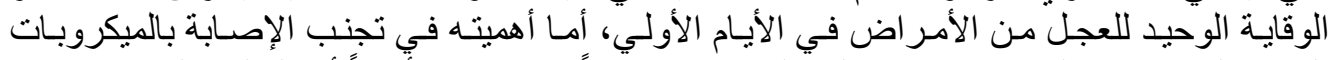

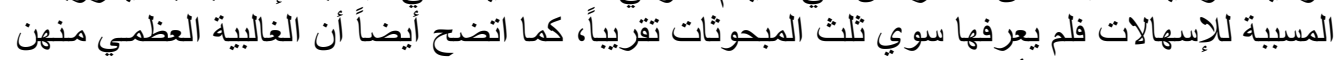

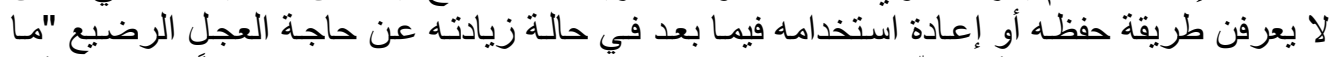

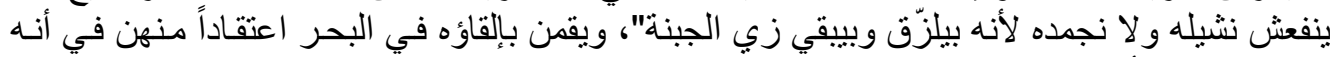

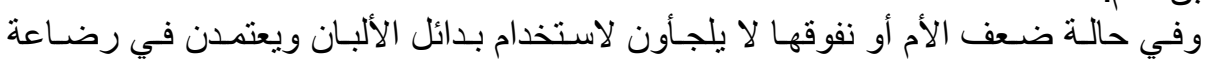

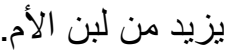

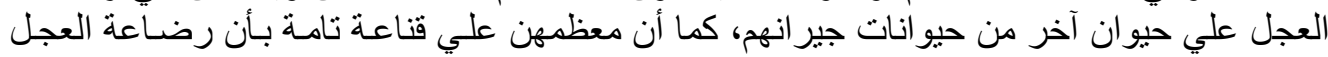

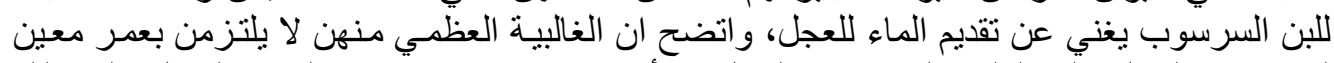

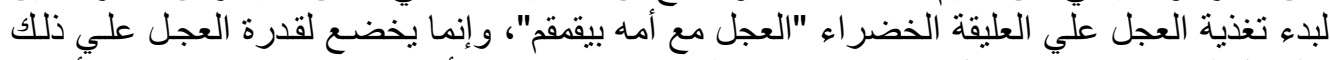

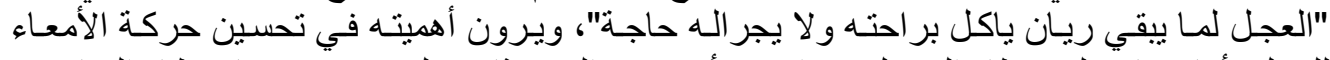

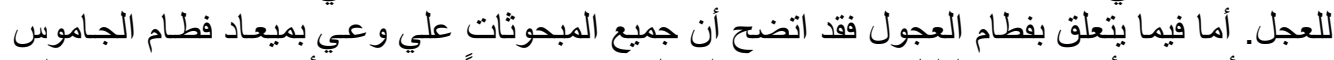

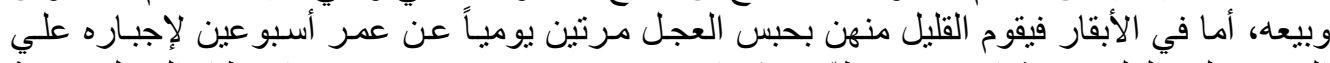

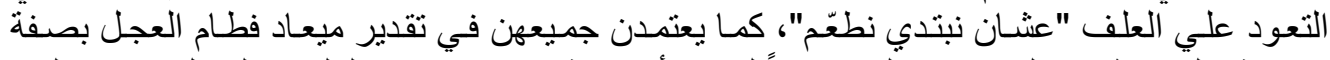

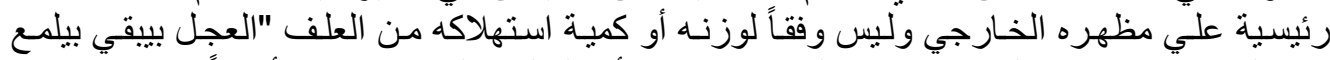

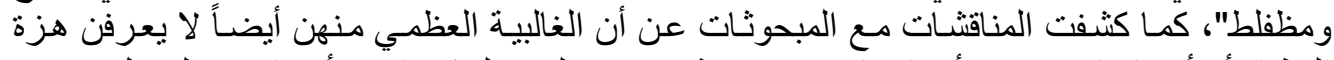

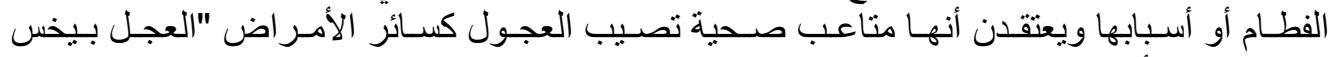

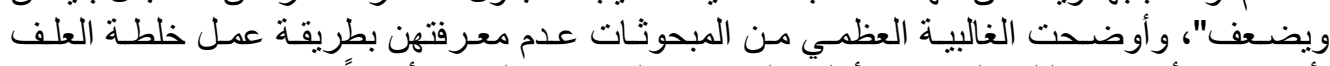

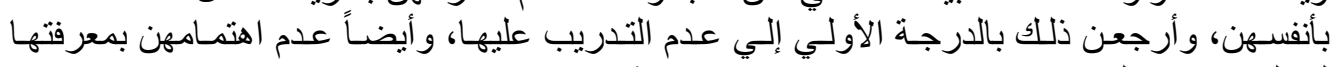

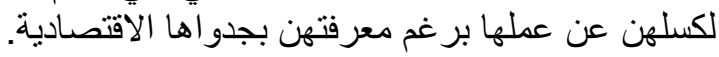

Fayoum J. Agric. Res. \& Dev., Vol. 27, No.1, January, 2013 


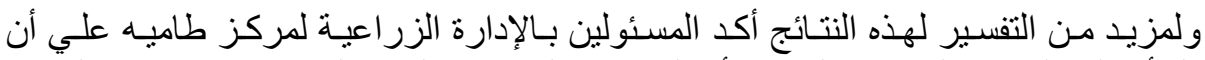

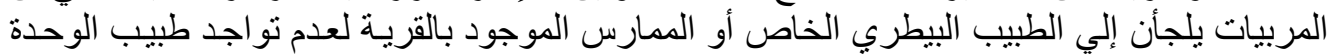

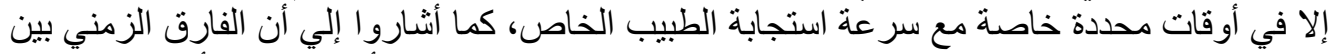

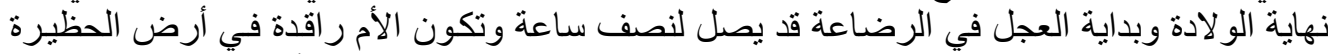

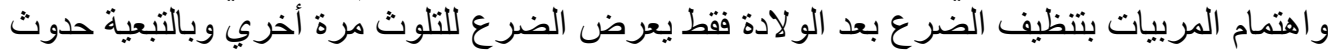

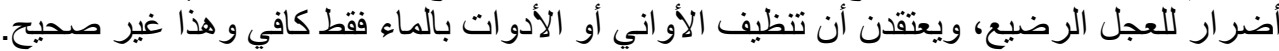

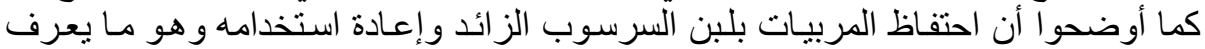

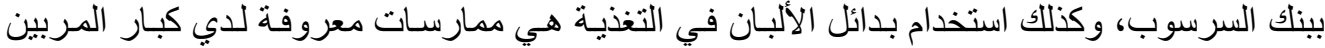

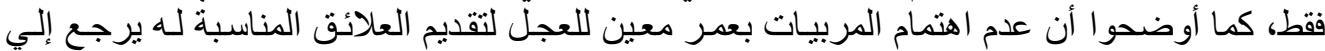

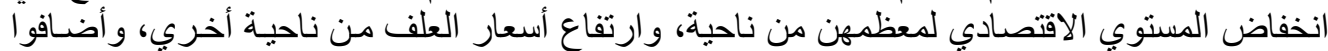

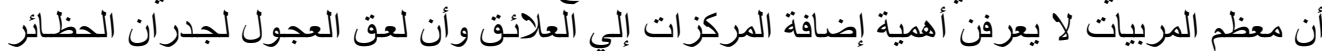

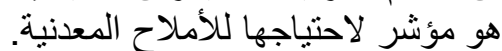

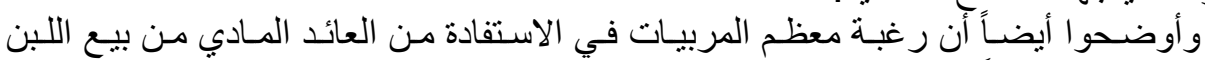

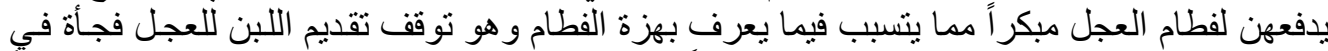

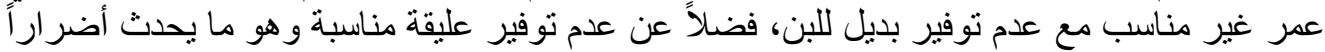

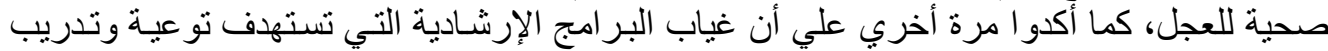

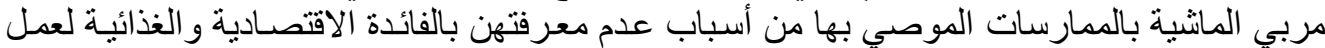

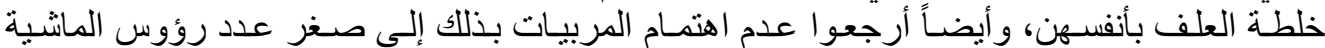

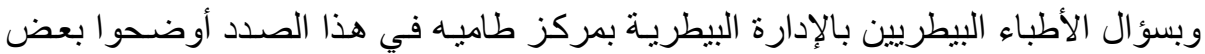
لايهن.

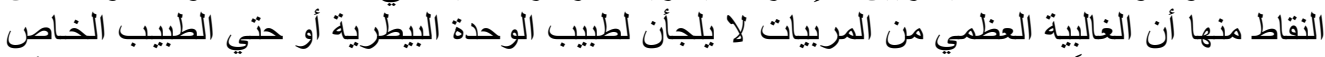

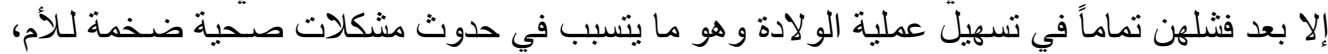

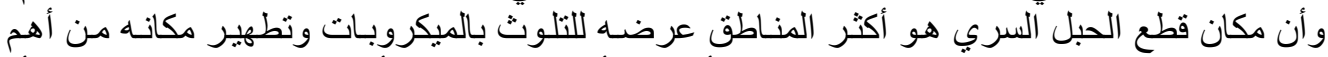

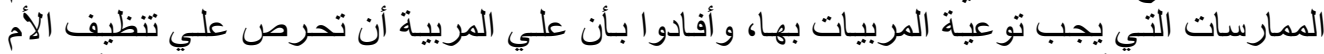

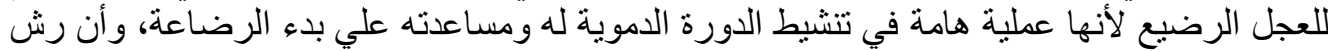

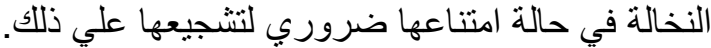

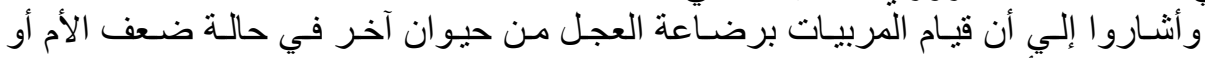

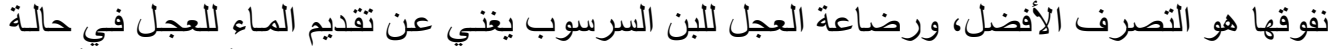

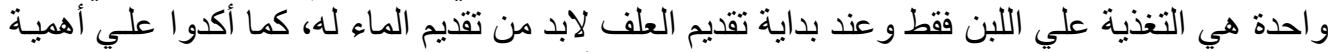

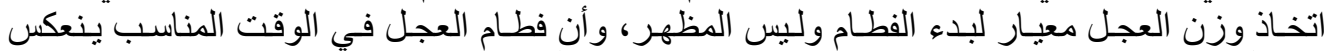

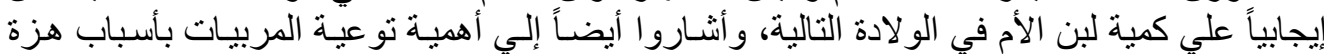

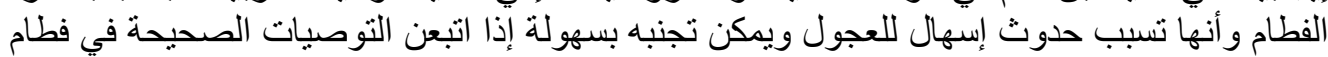

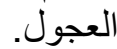

ويشير مستوي الفجوة الإرشادية المنخفض للمبحوثنات فيما يتعلق بهذا البند و الذي يسـاهم

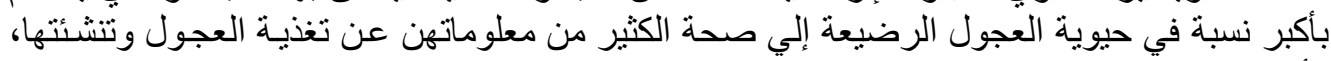

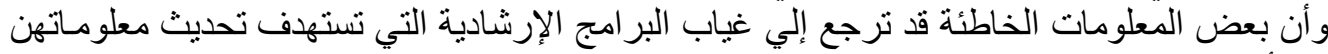

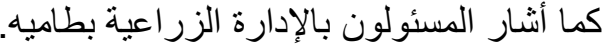

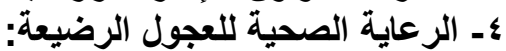

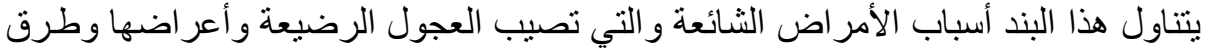

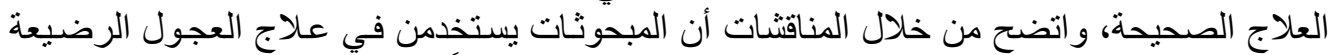

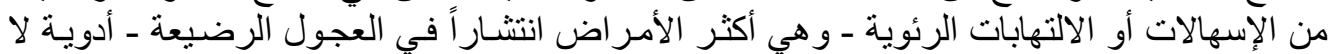

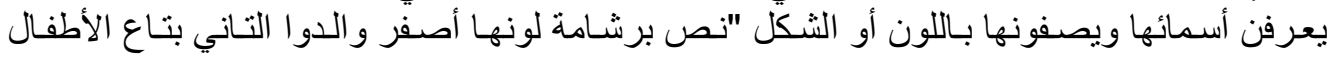

Fayoum J. Agric. Res. \& Dev., Vol. 27, No.1, January, 2013 
V9

عشان الإسهال"، ويعتمدن علي نصائح تجار الأدوية البيطرية في تحديد نوع العلاج وجر عته، و أخيراً

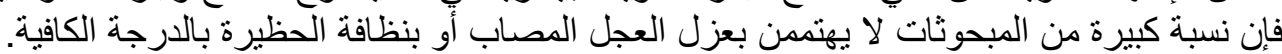

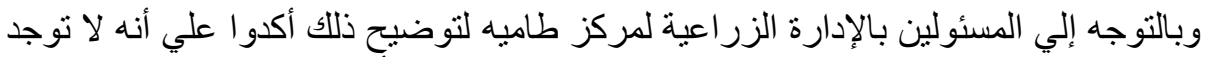

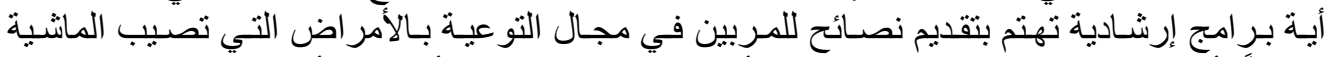

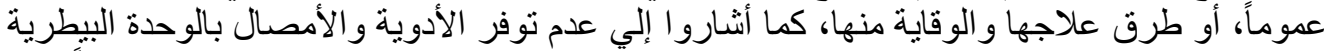

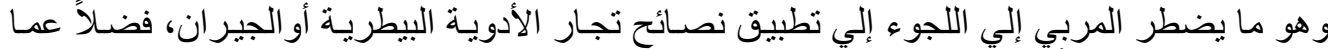

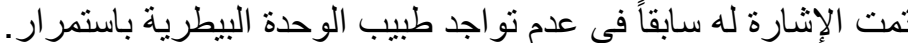

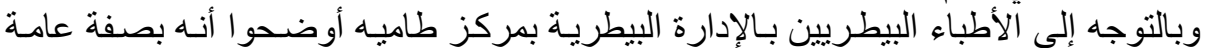

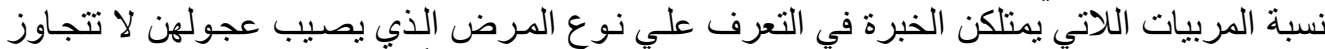

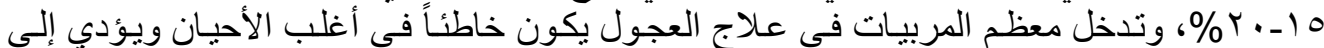

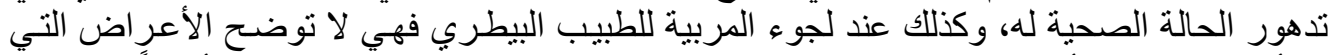

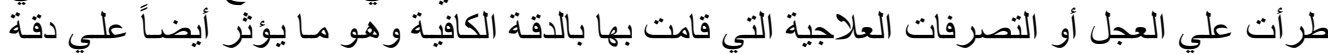

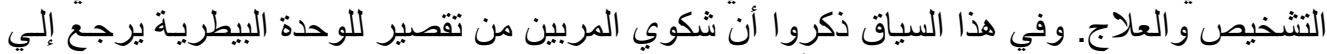

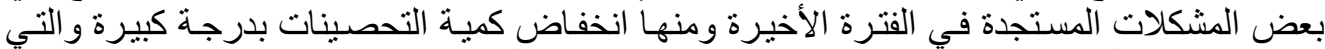

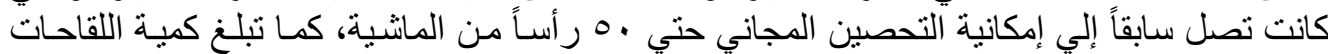

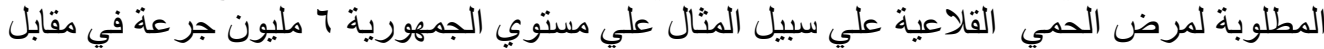

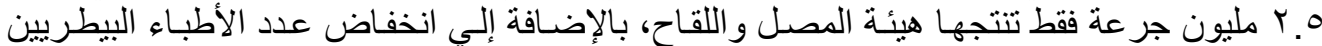
و العمال، وتهاللك الوحدات البيطرية.

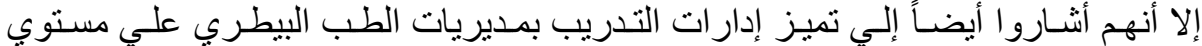

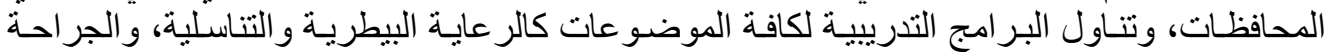

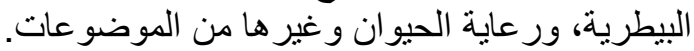

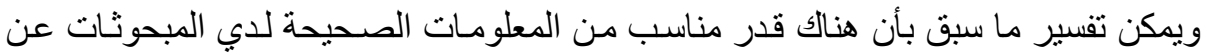

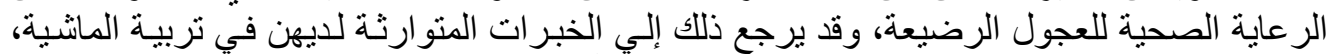

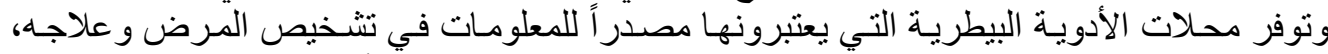

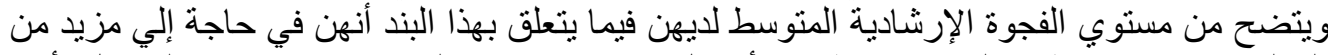

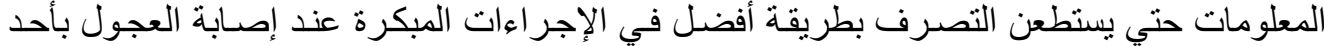

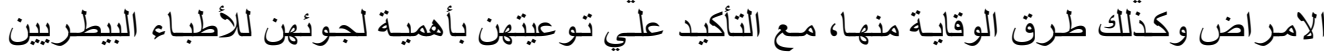

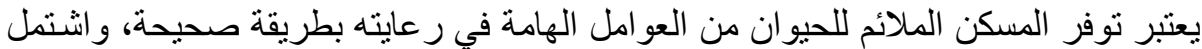

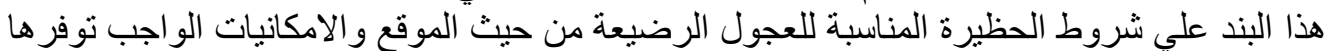

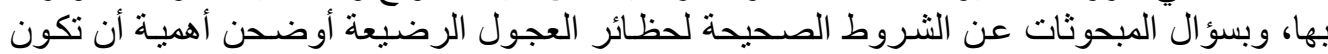

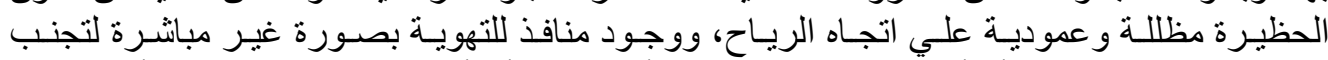

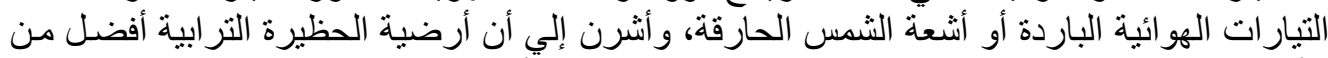

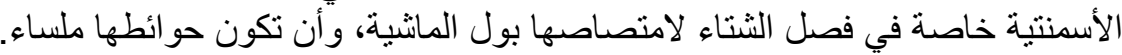

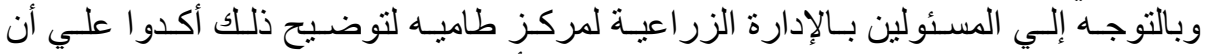

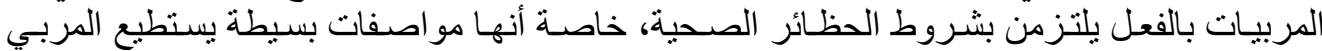
الصغير توفير هات بالفعل

وتثير نتائج مستوي الفجوة الإرشادية للمبحوثات في هذا البند إلي أن معلوماتهن صحيحة

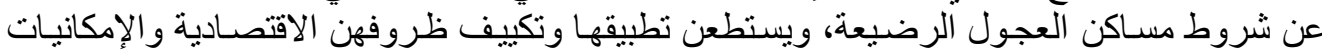
المتاحة لديهن لعمل الحظائر المناسبة. ثالثاً: المشكلات التي تواجه المربيات المبحوثات في مجال تفذية ورعاية العجول الرضيعة:

Fayoum J. Agric. Res. \& Dev., Vol. 27, No.1, January, 2013 
$\Lambda$.

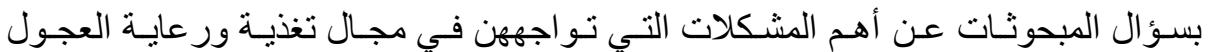

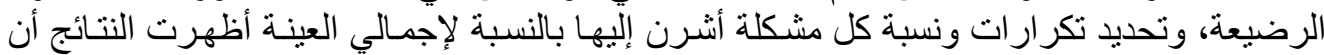

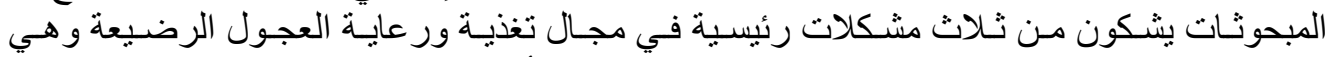

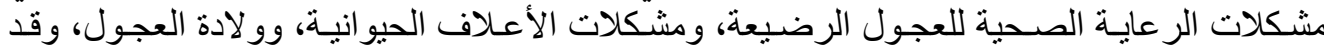

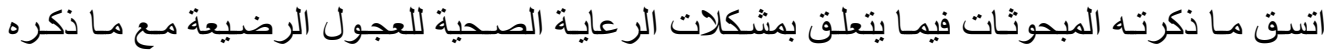

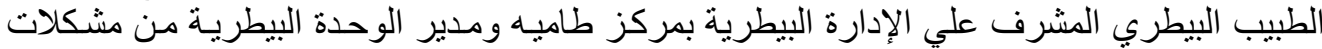

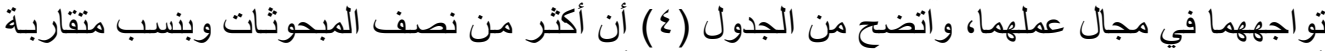

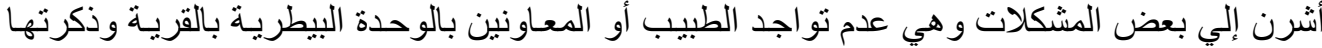

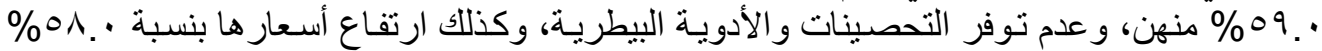

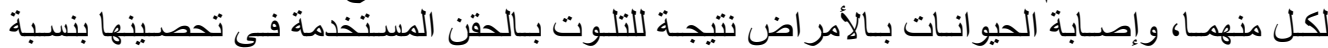

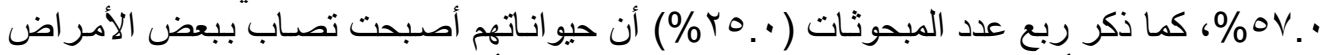

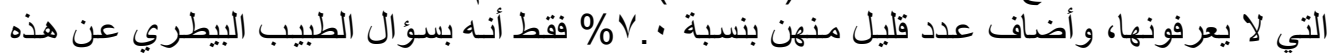

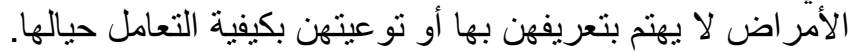

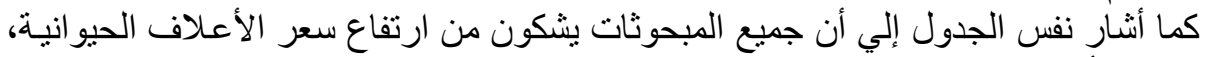

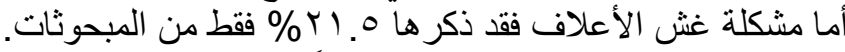

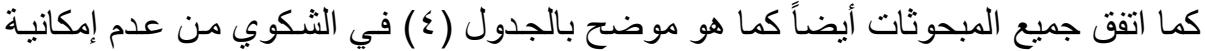

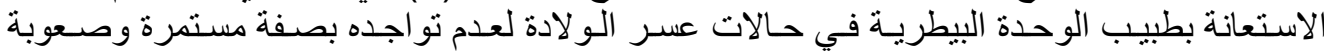
الوصول إليه، ويضطررن للجوء للطبيب البيطري الخاص وهو أمر مكلف بالنسبة لهن.

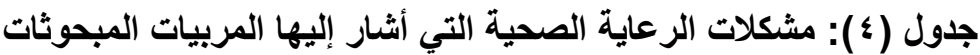

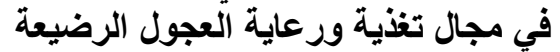

\begin{tabular}{|c|c|c|c|c|c|c|c|c|}
\hline$\%$ & 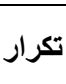 & مشكلات ولادة العجول & $\%$ & تكرار & مشكلات الأعلاف & $\%$ & 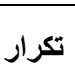 & مشكلات الرعاية الصحية \\
\hline \multirow[t]{6}{*}{$1 \ldots$} & $\Lambda \Lambda$ & 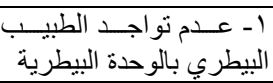 & $1 \ldots$ & $\Lambda \Lambda$ & ا - ارتفاع الأسعار & 09. & Or & 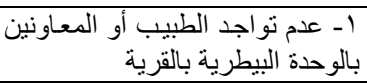 \\
\hline & & & r..0 & 19 & r- غش الأعلاف & 01. & 01 & 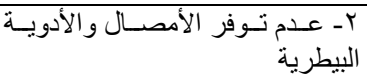 \\
\hline & & & & & & 01. & 01 & البيطر ارتفاع أسعار الأمصـال و الأدوية \\
\hline & & & & & & or. & 0 . & 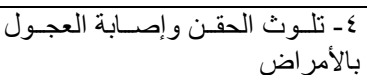 \\
\hline & & & & & & ro. & rY & 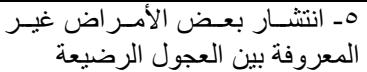 \\
\hline & & & & & & $v_{.} \cdot$ & 7 & 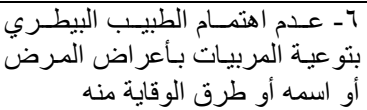 \\
\hline
\end{tabular}

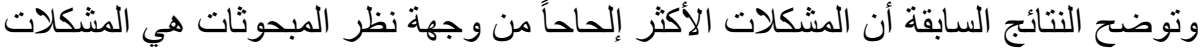

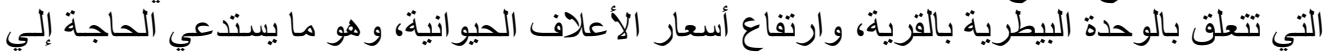

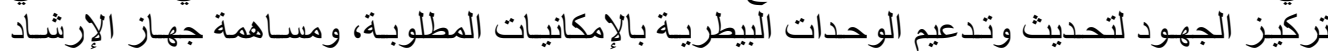

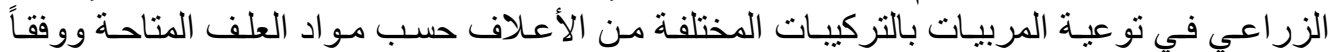
لأوضاعهن الاقتصادية.

رابعاً: مقترحات لتنمية معارف ومهار ات المربيات في مجال تغذية ورعاية العجول الرضيعة

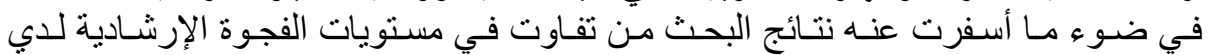

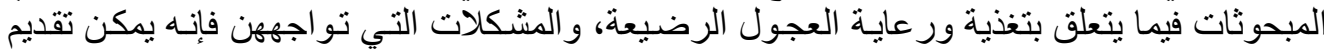

Fayoum J. Agric. Res. \& Dev., Vol. 27, No.1, January, 2013 
$\wedge$

بعض المقترحات التي يمكن أن تسـاهم في رفع المستوي المعرفي و المهاري للمربيـات ومسـاعدتهن

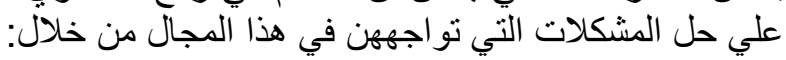

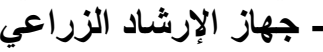

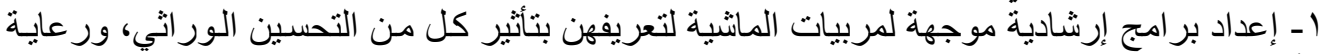

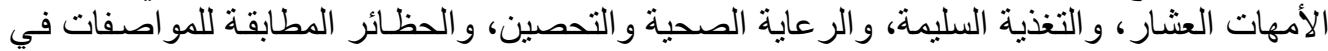

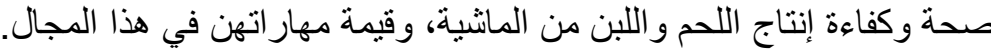

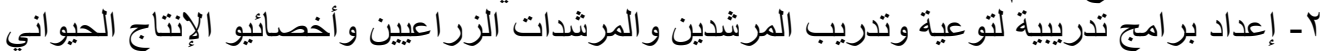

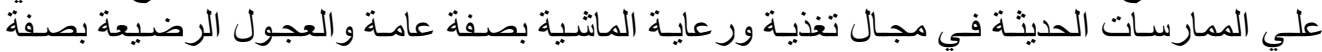

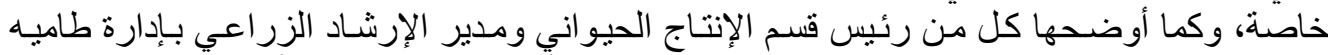

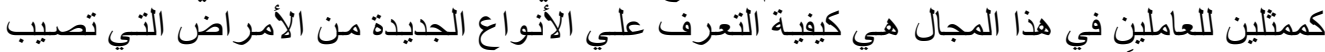

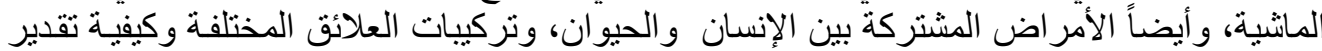

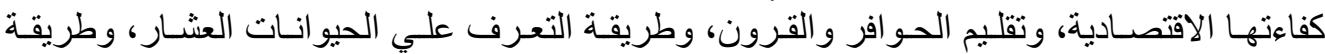
توليدها.

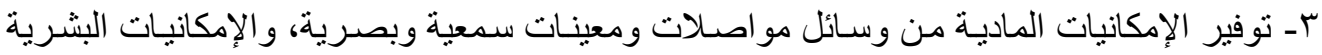

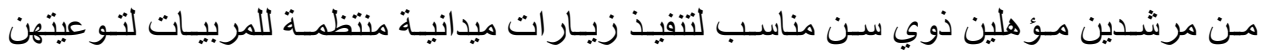

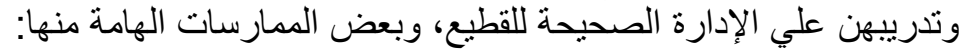

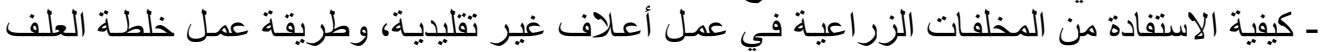

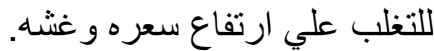

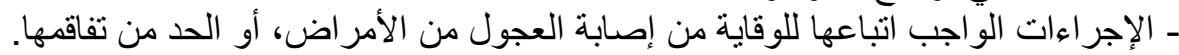

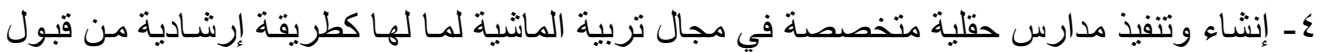

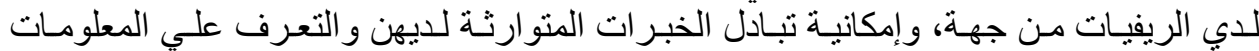

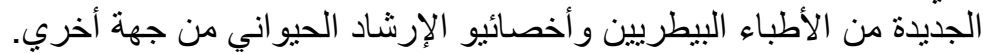

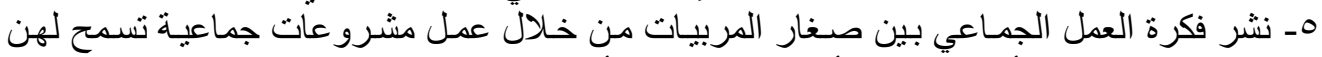

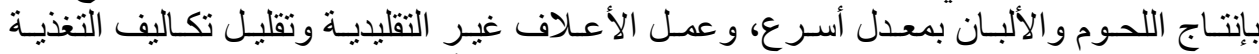

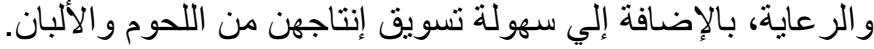

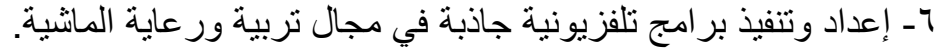

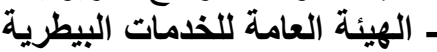
1 - تنفيذ زيار ات ميدانية دورية لتوعية صـغار المربيات بـالطرق الصحية في تربية ور عايـة العجول

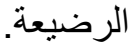

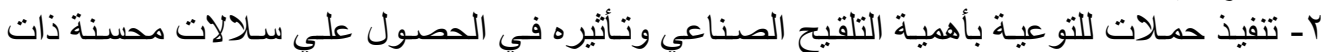

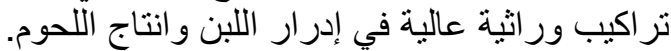

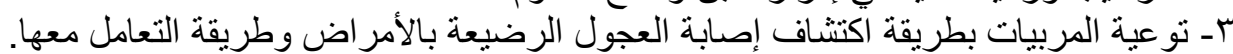

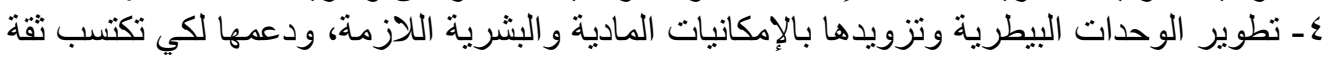

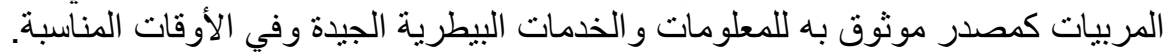

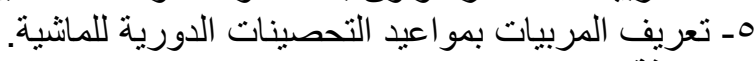

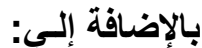

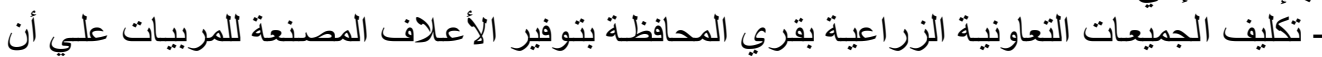

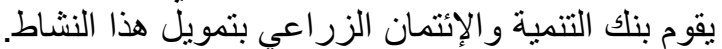

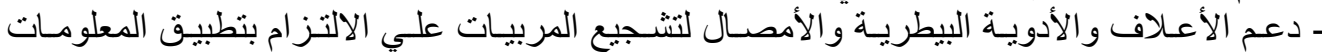
الصحيحة في تغذية الماثية. - دعم تقاوي الأصناف المحسنة من المحاصة الميل المستخدمة في تصنيع الأعلاف. - منح قروض ميسرة لتشجيع الريفيات علي تربية المانشية.

Fayoum J. Agric. Res. \& Dev., Vol. 27, No.1, January, 2013 
$\Lambda r$

- إعداد قاعدة بيانات دقيقة عن عدد صغار مربي ومربيات المانثية علي مستوي محافظة الفيوم حتي

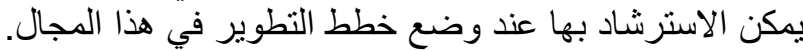

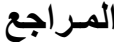

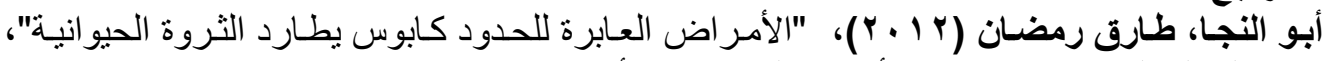

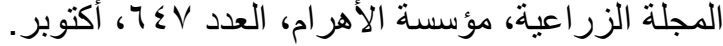

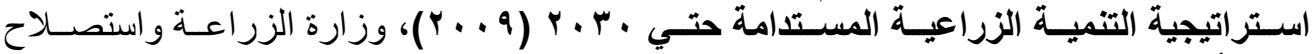

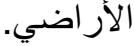

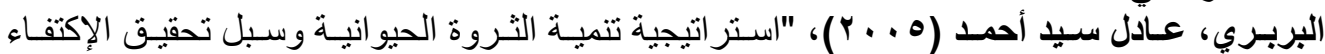

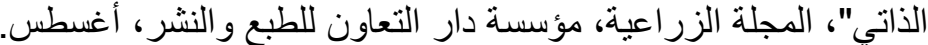

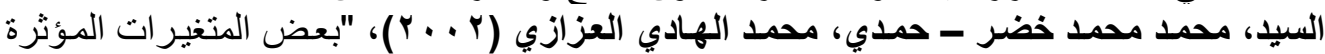

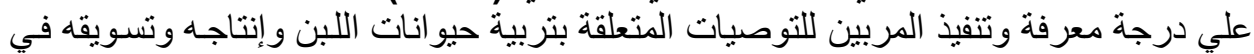

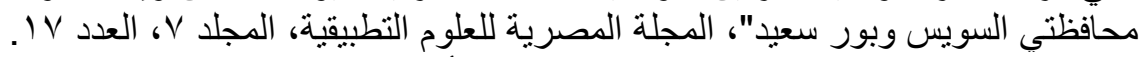

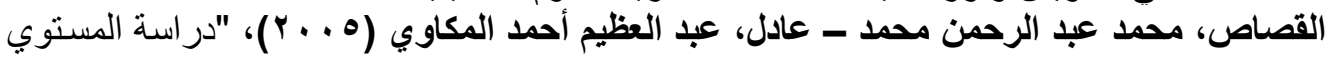

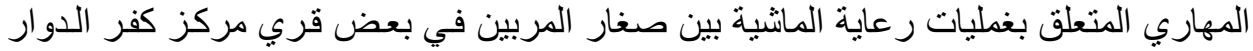
بمحافظة البحيرة"، مجلة الجديد في البحوث الزر اعية، كلية الزر اعلة، جامعة الإسكندرية، المجلد

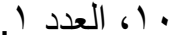

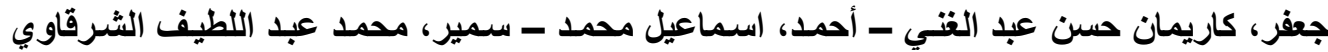

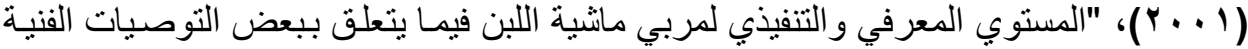

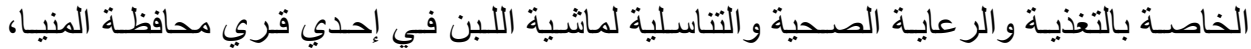

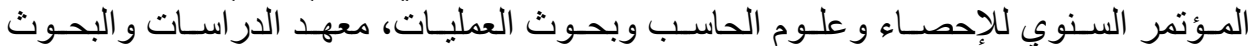
الإحصائية، جامعة القاهرة.

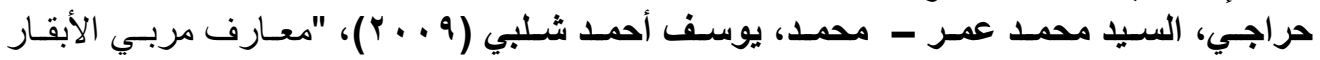

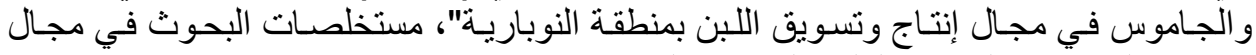

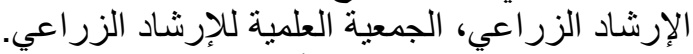

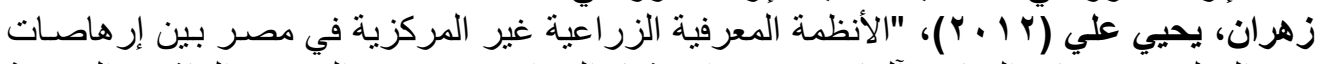

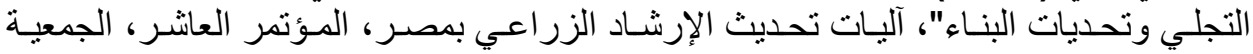

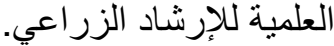

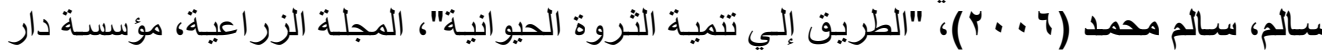

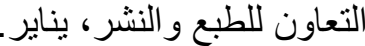

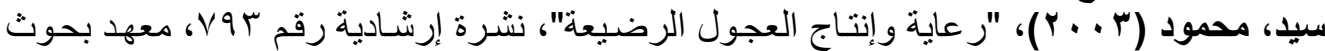

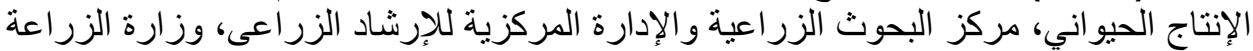

Available at:

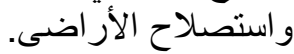

http://www.vercon.sci.eg/indexUI/uploaded/Smalcatle/smalcatle.htm visited in: $23 / 2 / 2013$

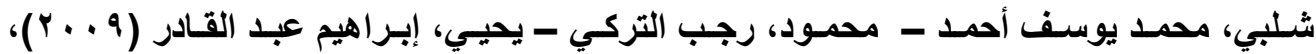

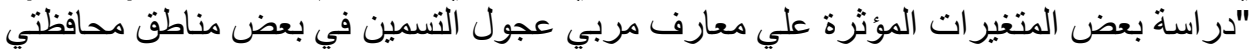

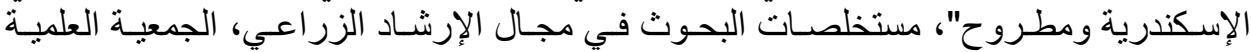

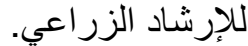

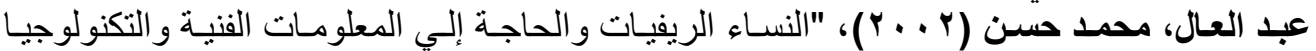

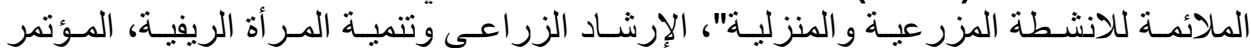

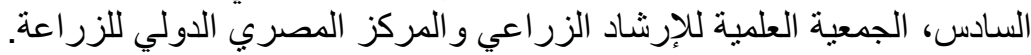

Fayoum J. Agric. Res. \& Dev., Vol. 27, No.1, January, 2013 


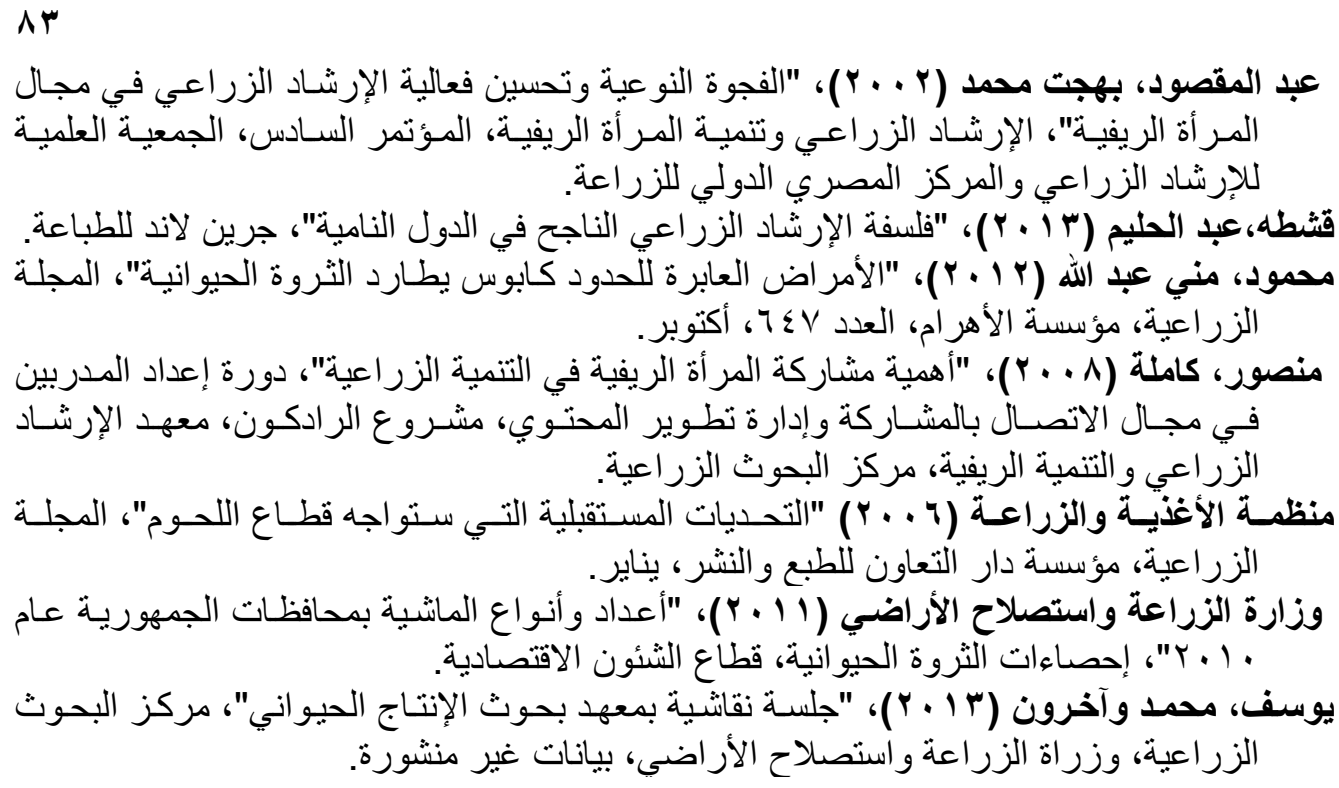

Israel, Glenn D., (-----), "Determining Sample Size", Florida University IFAS Extension.

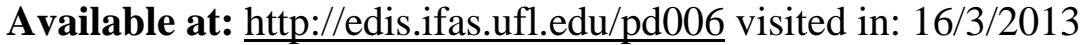

\section{CAUSES OF EXTENSION GAP OF BREEDERS IN THE FIELD OF FEEDING AND RAISING FOR SUCKLING CALVES IN EL- RODA VILLAGE IN FAYOUM GOVERNORATE}

Heba E. E. Ali Salama

Agricultural extension \& rural development research institute

\section{ABSTRACT}

Study aimed to determine extension gap to breeders regarding: genotype to mother and calf, care of mothers calves during pregnancy, feeding suckling calves, health care for suckling calves and calves housing, in addition to identify the most important problems facing breeders in this field. Finally, study aimed to present some suggestions to improve breeders' knowledge and skills in the field of feeding and raising for suckling calves.

Study was conducted in Fayoum governorate depending on informants, one district and one village was selected which is El- Roda- Tmia district. Random sample was selected from a woman of farmer's family which reached to 88 respondents. Data was collected through questionnaire which was pertested using personal interviews in addition, group discussions, depth interviews to clarify some details that can contribute to explanation results. To analyze data: mean, frequencies, standard deviation, and percentages were used.

\section{The study findings revealed that:}

Fayoum J. Agric. Res. \& Dev., Vol. 27, No.1, January, 2013 
$\Lambda \varepsilon$

1- Extension gap level was high regarding Genotype of mother and calf (97\%), average regarding care of the mother calves during pregnancy $(72 \%)$ and health care for sucking calves (69\%), while extension gap level was low regarding both of feeding \& bringing up suckling calves (49\%) and suckling calves housing (0).

2- Causes of extension gap by breeders could be summarized as follow: unavailability of sufficient information, their conviction of some incorrect ideas and practices, effect of their low economic level to take some appropriate decisions, lack of communication and lack of confidence in the veterinary unit.

3- Most important problems facing respondents were problems of health care for suckling calves which include non-existence of a doctor or assistants in the veterinary unit of the village (59.0\%), unavailability of immunizations and veterinary medicines $(58.0 \%)$ and its high prices $(58.0 \%)$, in addition animal injury by diseases as a result of infection of used injection $(57.0 \%)$. As well as the problem of high price of animal feed (100\%) and cheat animal feed $(21.5 \%)$. Also all respondents (100\%) agree inability of access to the veterinarian in cases of dystocia.

Fayoum J. Agric. Res. \& Dev., Vol. 27, No.1, January, 2013 